\title{
High-level studies of the ionic states of norbornadiene and quadricyclane, including analysis of new experimental photoelectron spectra by configuration interaction and coupled cluster calculations.
}

Michael H. Palmer, ${ }^{1, a}$ Marcello Coreno, ${ }^{2, b}$ Monica de Simone, ${ }^{3, b}$ Cesare Grazioli, ${ }^{3, b}$ R. Alan Aitken, ${ }^{4}$ Søren Vrønning Hoffmann,,${ }^{5, b}$ Nykola C. Jones ${ }^{5, b}$ and Coralyse Peureux. ${ }^{4}$

${ }^{1}$ School of Chemistry, University of Edinburgh, Joseph Black Building, David Brewster Road, Edinburgh EH9 3FJ, Scotland, UK

${ }^{2}$ ISM-CNR, Istituto di Struttura della Materia, LD2 Unit 34149 Trieste, Italy, ${ }^{3}$ IOM-CNR Laboratorio TASC, Trieste, Italy

${ }^{4}$ School of Chemistry, University of St Andrews, North Haugh, St Andrews, Fife, KY16 9ST, Scotland, UK.

${ }^{5}$ ISA, Department of Physics and Astronomy, Aarhus University, Ny Munkegade 120, DK-8000, Aarhus C, Denmark

a) Email: m.h.palmer@ed.ac.uk:

b) Electronic addresses: marcello.coreno@elettra.eu; desimone@iom.cnr.it; grazioli@ism.cnr.it; raa@st-andrews.ac.uk; vronning@phys.au.dk; nykj@phys.au.dk; coralyse.peureux@laposte.net

\section{ABSTRACT}

Synchrotron-based photoelectron spectra (PES) of norbornadiene (NBD) and quadricyclane (QC) differ significantly from previous studies. The adiabatic ionization energy ( $\mathrm{AIE}_{1}$ ) for $\mathrm{NBD}$, assigned to the ${ }^{2} \mathrm{~B}_{1}$ state at $8.279 \mathrm{eV}$, shows a progression of 18 members, with decreasing vibration frequency from 390 to $340 \mathrm{~cm}^{-1}$; our calculated frequency is $381 \mathrm{~cm}^{-1}$. Similarly, the $\mathrm{AIE}_{1}$ for $\mathrm{QC}$ at $7.671 \mathrm{eV}$, assigned to the ${ }^{2} \mathrm{~B}_{2}$ state, discloses a vibrational progression of 9 or more members, with vibration frequency decreasing from 703 to $660 \mathrm{~cm}^{-1}$; Our calculated vibration frequency is $663 \mathrm{~cm}^{-1}$. These AIE, determined by coupled cluster and $4^{\text {th }}$ order Møller-Plesset perturbation theory, were very similar to the corresponding 2nd order perturbation theory results. The calculated AIE symmetry sequences are NBD: ${ }^{2} \mathrm{~B}_{1}<{ }^{2} \mathrm{~A}_{1}<{ }^{2} \mathrm{~A}_{2}$ $<{ }^{2} \mathrm{~B}_{2}$, and QC: ${ }^{2} \mathrm{~B}_{2}<{ }^{2} \mathrm{~A}_{2}<{ }^{2} \mathrm{~B}_{1}<{ }^{2} \mathrm{~A}_{1}$. The overall PES vertical ionization energy profiles for 
both compounds were closely reproduced by Tamm-Dancoff approximation energies and intensities. The vibrational structure of the ionic states, determined using Franck-Condon methods, gave a good account of the observed spectra, but the observed envelopes for both IE 1 are complex sets of vibrations, rather than single progressions. The NMR spectra for QC showed residual $2^{\text {nd }}$ order properties at $300 \mathrm{MHz}$; both it and NBD, have been theoretically analysed in greater detail as $\mathrm{AA}^{\prime} \mathrm{BB}^{\prime} \mathrm{CC}^{\prime} \mathrm{XX}^{\prime}$ spectra, where all $\mathrm{H}$ are coupled; the magnetic shielding and spin-spin coupling constants obtained are similar to experimental values.

\section{INTRODUCTION}

Recently, we reported new high-resolution photoelectron spectra (PES) of cyclooctatetraene $\left(\mathrm{C}_{8} \mathrm{H}_{8}, \mathrm{COT}\right)^{1}$ and cycloheptatriene $\left(\mathrm{C}_{7} \mathrm{H}_{8}, \mathrm{CHT}\right) .{ }^{2}$ These were analyzed in considerable detail by a combination of Møller-Plesset $4^{\text {th }}$ order perturbation theory, which included single, double and quadruple substitutions (MP4(SDQ)), configuration interaction (CI), multi-configuration self-consistent field (MCSCF) and density functional theoretical methods (DFT). ${ }^{1,2}$ These studies were followed by detailed analyses of new vacuum ultraviolet (VUV) absorption spectra for both compounds, using closely related theoretical methods. ${ }^{3,4}$

We now present new synchrotron based PES for both norbornadiene (NBD) and quadricyclane (QC). Interconversions between NBD and QC are important in two potentially industrial and commercial applications which are noted below. The present compounds lack conjugated double bonds, as shown in Figure 1, but are isoelectronic with CHT.

One application of the NBD+QC binary system enables solar energy storage in a single molecular system. ${ }^{5-8}$ Another application is as a switch for an optical memory system. ${ }^{9,10}$ NBD is converted to its valence isomer $\mathrm{QC}$, via an endothermic photoinduced $[2+2]$ reversible cycloaddition. ${ }^{11}$ Thermal or catalytic induction leads to the reverse reaction, where QC regenerates NBD with release of heat. When triplet sensitized using acetophenone, the NBD process appears to involve the two triplets, ${ }^{3} \mathrm{NBD}$ and ${ }^{3} \mathrm{QC}$, followed by relaxation to $\mathrm{QC},{ }^{12}$ but 
not all sensitizers behave similarly. During the NBD $\leftrightarrows$ QC process, up to $100 \mathrm{~kJ} / \mathrm{mol}$ of chemical energy is stored, a value comparable to contemporary batteries. ${ }^{13}$ The main wavelengths of sunlight lie between 300 and $700 \mathrm{~nm}$. Since the NBD UV onset is $267 \mathrm{~nm}$, a combination of donor and acceptor groups in the NBD+QC system is necessary to give an improved solar spectrum match; examples have been reported with an onset of absorption up to $529 \mathrm{~nm} .{ }^{11,14,15}$

When NBD, or its derivatives, are converted to the corresponding QC on irradiation, the 'OFF' form of the photo-switch occurs. Conversion back to the NBD, gives the 'ON' form of the switch. In order to release the stored energy as electricity, the photo-switch must interact with a semiconducting electrode surface. ${ }^{13}$

The technological aspects of the NBD $\leftrightarrows$ QC equilibrium lie outside the scope of the current paper, but the electronic states of the neutral and ionic states for the parent molecules of NBD and QC are crucial to understanding these more complex interactions; our work is directed to performing this at a more rigorous level than is currently available. As with CHT and COT previously, the VUV spectra of NBD and QC will be presented in a following paper, which will analyze the VUV spectra in a detailed manner.

For both title compounds, we have determined the lowest observed adiabatic ionization energies (AIE) of each symmetry, using calculations at both the coupled cluster level, including single, double and quadruple excitations and non-iterative triples $(\operatorname{CCSD}(\mathrm{T}))$ and MP4(SDQ) levels. We will show that the results for these two hydrocarbons, as the basis set is changed are very similar, and also to those at the MP2 level. The profiles of both photoelectron spectra will be interpreted up to about $20 \mathrm{eV}$ by the Tamm Dancoff approximation (TDA), a 
single excitation configuration interaction (CI) method. Franck-Condon analyses will be performed on the vibrational structure of several ionic states in each series.

During the synthetic phase of the investigation, it became clear that the ${ }^{1} \mathrm{H}$ NMR spectrum of QC, previously studied at lower frequencies, such as $60 \mathrm{MHz}$, were incompatible with those at $300 \mathrm{MHz}$. The change in appearance of the spectra is considerable, since the 3-membered rings of QC lead to nearly degenerate ${ }^{1} \mathrm{H}$ NMR signals at low frequencies, and hence uncertainty in assignment. Further, the NMR spectra of QC even at $300 \mathrm{MHz}$ showed additional line splitting, arising from $2^{\text {nd }}$ order effects. Since previous study of QC had only been analyzed by $1^{\text {st }}$ order methods, a full theoretical $2^{\text {nd }}$ order analysis, under conditions where all spin-spin interactions are included, was performed.

Previous work has shown that the PES of NBD and QC are distinct in the gas phase. ${ }^{16-21}$ Similarly, chemically induced dynamic nuclear polarization (CIDNP), following chloranil photosensitization, confirms the difference in solution. Electron spin resonance (ESR) spectra and equilibrium structure calculations, indicate symmetrical, but clearly different structures, for the NBD and QC radical cations. ${ }^{22-25}$ Much of the early experimental ionization data and theoretical interpretations for NBS and QC, is summarised in the NIST webbook. ${ }^{26}$

Figure 1. The compounds norbornadiene (NBD) and quadricyclane (QC). The classical bond switching between the two systems $(1 \mathrm{a}, 1 \mathrm{~b})$ occurs during UV excitation. Rotation of the orbitals towards each other $(1 \mathrm{c}, 1 \mathrm{~d})$ leads to closure to the double cyclopropane system of QC. 

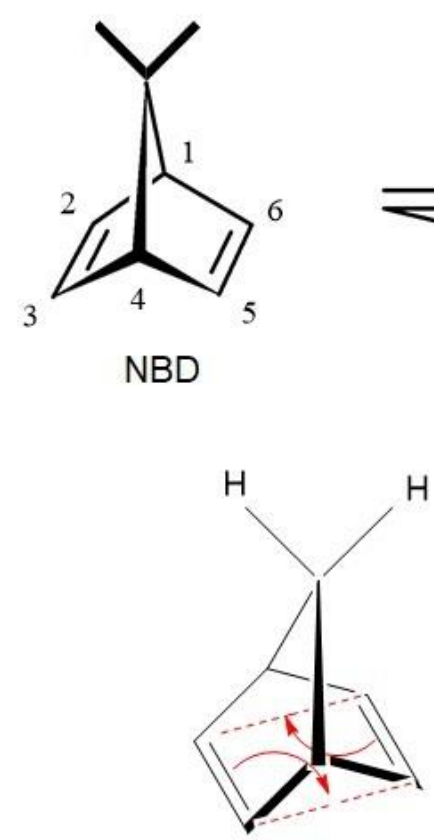

1a, NBD

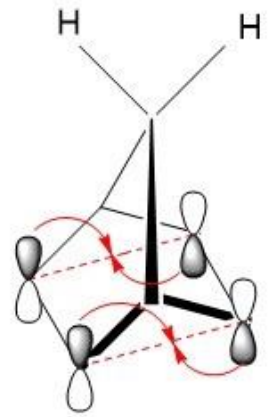

1c, HOMO

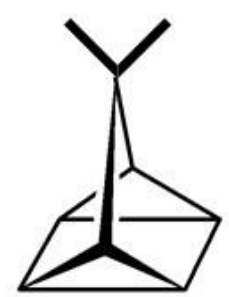

QC

$\Delta$

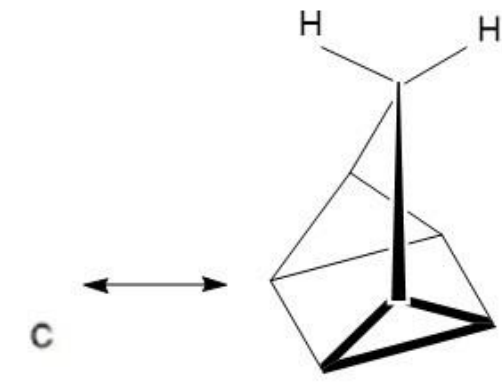

$1 \mathrm{~b}, \mathrm{QC}$
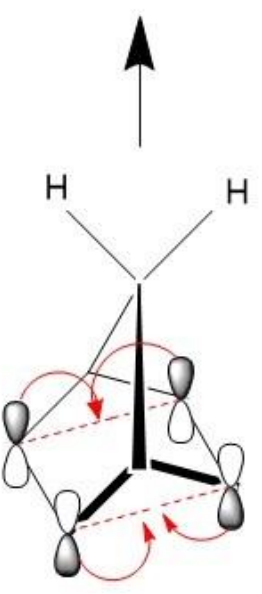

1d, LUMO

\section{METHODS}

NBD has CAS registry number 121-46-0 and systematic name bicyclo[2.2.1]hepta-2,5-diene.

QC has CAS registry number 278-06-8, where it is named tetracyclo[2.2.1.0 $\left.0^{2,6} .0^{3.5}\right]$ heptane. This systematic numbering leads to both NBD and QC having a 7- $\mathrm{CH}_{2}$ group, which enables us to retain the relationship between both compounds. However, an alternative IUPAC nomenclature names QC as tetracyclo[3.2.0.0 $\left.0^{2,7} \cdot 0^{4,6}\right]$ heptane, which leads to a 3- $\mathrm{CH}_{2}$ group; this difference to NBD is inconvenient and we adopt the 7- $\mathrm{CH}_{2}$ group labelling. 
A commercial sample of NBD from Sigma-Aldrich was used after detailed ${ }^{1} \mathrm{H}$ NMR analysis. We found that the chemical shifts and spin coupling constants previously reported ${ }^{27-31}$ at 60 and $100 \mathrm{MHz}$ for NBD accurately reproduced the $300 \mathrm{MHz}{ }^{1} \mathrm{H}$ NMR spectrum, but this was not the case for QC, as discussed below.

A. Synthetic methods. QC was prepared from NBD by irradiation, using a water-cooled

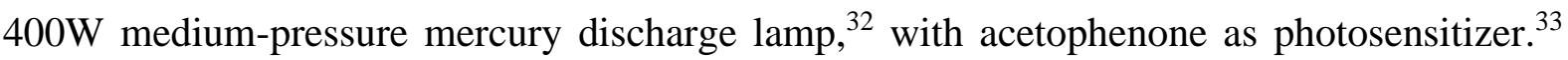
Fractional distillation of the reactant mixture gave QC, but was contaminated by $\sim 5 \%$ unchanged NBD. This sample was used in the spectroscopy below, since the signals do not interfere with the spectroscopy. Further details are also given in the Supplementary Material as SM1.The QC ${ }^{1} \mathrm{H}$ NMR spectrum at $300 \mathrm{MHz}$ showed chemical shifts $(\delta)$ at $2.02(2 \mathrm{H}, \mathrm{t}, \mathrm{J}=1.5$ $\left.\mathrm{Hz}, \mathrm{CH}_{2}\right), 1.48-1.50(4 \mathrm{H}, \mathrm{m})$ and $1.34-1.38 \mathrm{ppm}(2 \mathrm{H}, \mathrm{m})$, where ' $\mathrm{t}$ ' and ' $\mathrm{m}$ ' are triplet and multiplet, in agreement with the literature. ${ }^{34,35}$ Although ${ }^{13} \mathrm{C}-{ }^{1} \mathrm{H}$ coupling constants have previously been reported for QC, ${ }^{36,37}$ the new spectrum for QC allowed detailed analysis and determination of additional ${ }^{1} \mathrm{H}-{ }^{1} \mathrm{H}$ and ${ }^{13} \mathrm{C}-{ }^{1} \mathrm{H}$ coupling constants for the first time.

B. The photoelectron spectra of NBD and QC. These were obtained at room temperature on the gas-phase line of the Elettra synchrotron (Basovizza, near Trieste, Italy), using methods described previously. ${ }^{1,3}$ The NBD sample vapour was irradiated at both $30 \mathrm{eV}$ and $95 \mathrm{eV}$ photon energy. The $30 \mathrm{eV}$ spectrum, covers the energy range 7.473 to $16.473 \mathrm{eV}$ with 5670 data points (DPs), separated by $0.001 \mathrm{eV}\left(8 \mathrm{~cm}^{-1}\right)$; this corresponds to a total resolution close to $8.5 \mathrm{meV}$. A wider NBD scan up to $24.473 \mathrm{eV}$, also using $30 \mathrm{eV}$ irradiation, contained 10471 DPs, with a separation of $0.0025 \mathrm{eV}\left(20 \mathrm{~cm}^{-1}\right)$. The $95 \mathrm{eV}$ scan for NBD contained $7500 \mathrm{DPs}$, with a separation of $0.005 \mathrm{eV}$ above $14.428 \mathrm{eV}$. The PES spectrum of QC up to $21.8 \mathrm{eV}$ measured using $30 \mathrm{eV}$ photons contained $9463 \mathrm{DP}$ with a separation of $0.002 \mathrm{eV}\left(16 \mathrm{~cm}^{-1}\right)$. The $30 \mathrm{eV}$ PES spectra for NBD and QC, in the 7.5 to $22 \mathrm{eV}$ energy range, are super-imposed in Figure 2; the substantial differences support previous conclusions that the two compounds 
are distinct in the gas phase. The onset for QC, slightly lower than that for NBD, is unexpected in view of its saturated QC structure.

Figure 2. The photoelectron spectra of norbornadiene (in blue) shown with the quadricyclane spectrum (in red). The onset of the formally saturated hydrocarbon (QC) lies below that for the non-conjugated alkene (NBD).

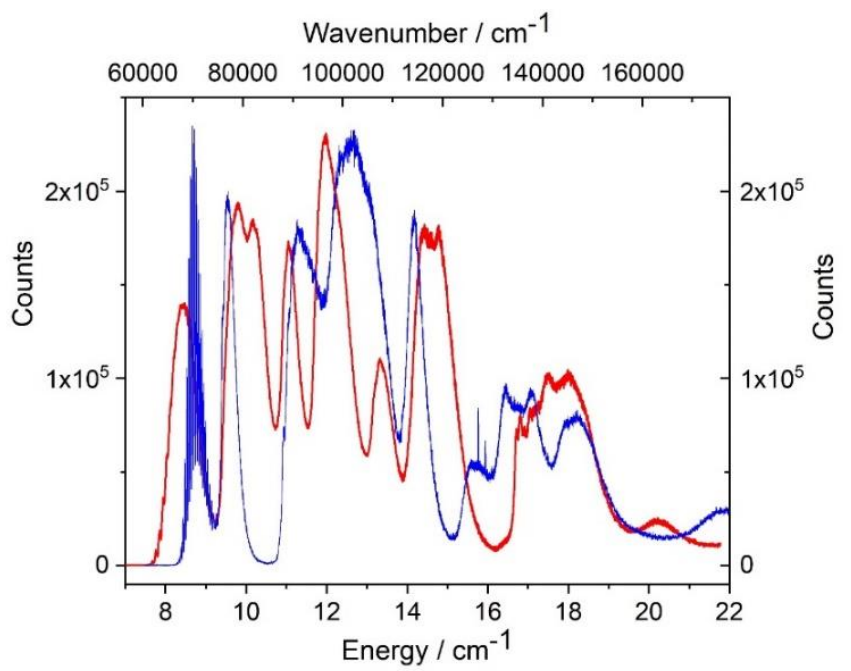

1. Norbornadiene. Expansion of the lowest IE, as in Figure 3, shows a considerable number of vibrational states, not reported in earlier spectra. It is clear that this band is not a single mode sequence with increasing quanta. Hence discussion in relation to the neutral state vibrations is irrelevant. This band is discussed in further detail below. The lowest AIE of NBD appears to lie at $8.279 \mathrm{eV}$. Since the onsets for most of the higher PES bands are not welldefined, these are best described by their vertical ionization energy (VIE). Our NBD analysis, by fitting Gaussian peaks to the low-lying ionizations gives a close fit to the observed PES, as shown in Figure 4. VIE2 shows a shoulder on its leading edge, which we attribute to a group of vibrational states, rather than a separate IE. The fitted peak maxima, which we identify as the VIEs, are discussed below. Further details of the NBD analysis, together with those for QC, are shown in the supplementary material as SM2.

Figure 3. The lowest ionic state of norbornadiene with vertical ionization energy at 8.6673 $\mathrm{eV}\left(69908 \mathrm{~cm}^{-1}\right)$ is shown in black with the Franck-Condon profile superimposed in red. 
Each of the apparent single sequence of vibrational bands is a progressively more complex set of vibrational states as the energy increases. The AIE is probably at 8.2799 $\mathrm{eV}\left(66783 \mathrm{~cm}^{-1}\right)$, the first recognisable member of the initial $392 \mathrm{~cm}^{-1}$ sequence.

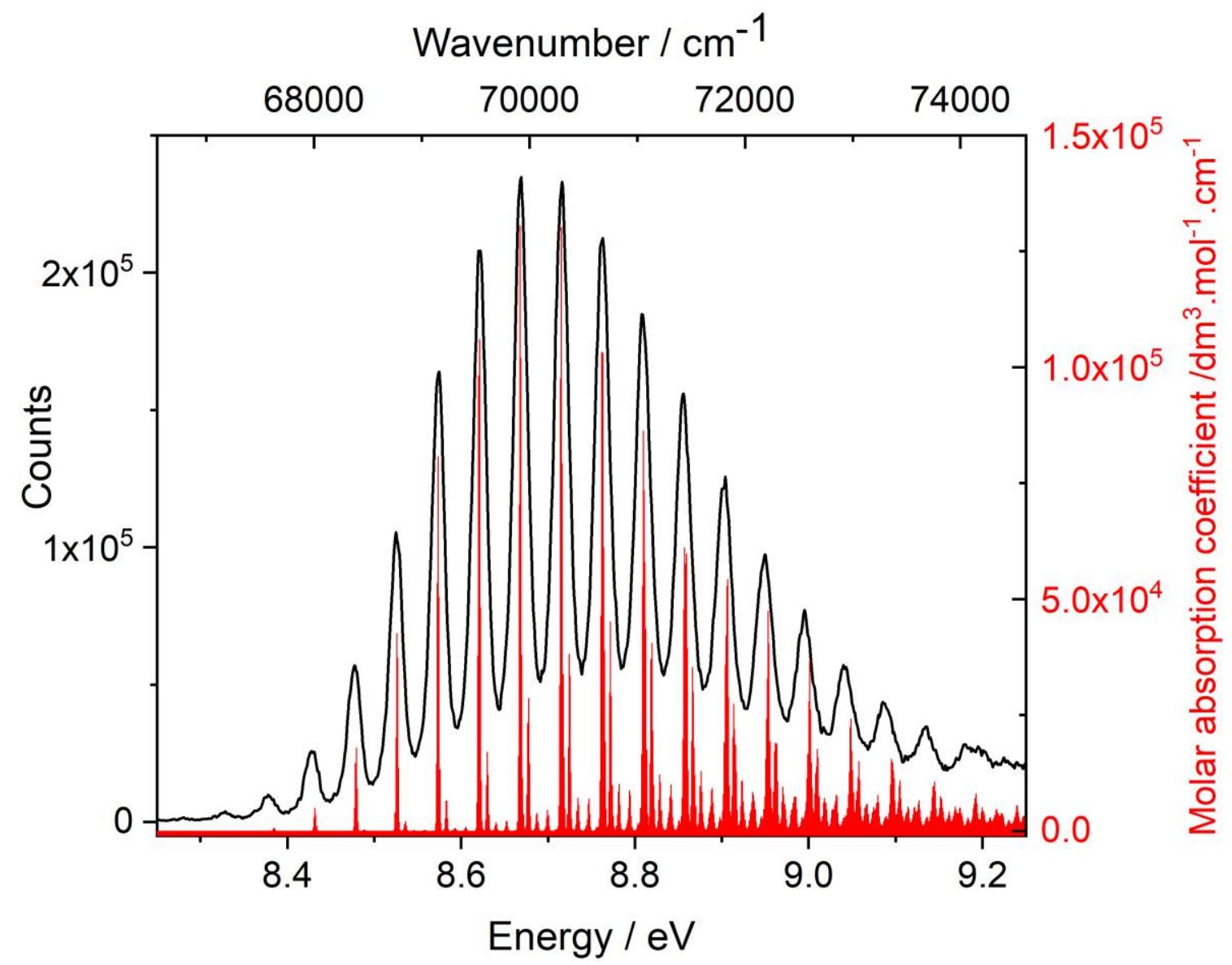

Figure 4. Detailed analysis of the lowest ionization energy for norbornadiene. The very low levels of residuals (Diff) after fitting are shown in red. Further details of the fit are shown in the supplementary material as SM3. 


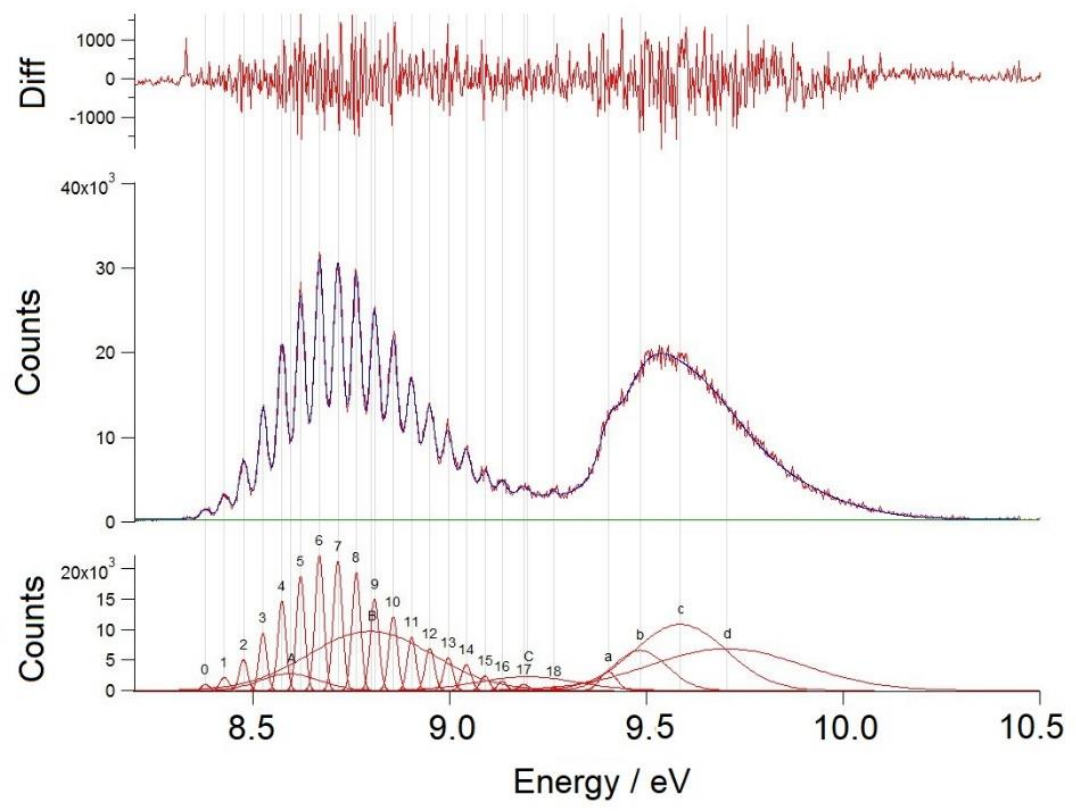

2. Quadricyclane. Most of the PES shows little evidence of vibrational structure, but the vibrations shown on the leading edge of $\mathrm{AIE}_{1}$ are quite different from those on the trailing edge, which are attributed to the small NBD contamination. This is discussed in more detail below. We compare the vibrations on the leading edge with calculated values below, but the spacing of these clearly relate to QC and not NBD. The overall structure of the QC PES lowest IE, can best be fit by a group of three asymmetric Gaussian functions, as in Figure 5 .

Figure 5. Detailed analysis of the lowest ionization energy for quadricyclane using $30 \mathrm{eV}$ irradiation, with overall resolution $10 \mathrm{meV}$; the sample contains approximately $5 \% \mathrm{NBD}$. It is not known whether this represents an equilibrium between the two compounds. The peaks for NBD are marked 12 to 27. Further details of the fit are shown in the supplementary material as SM3. 


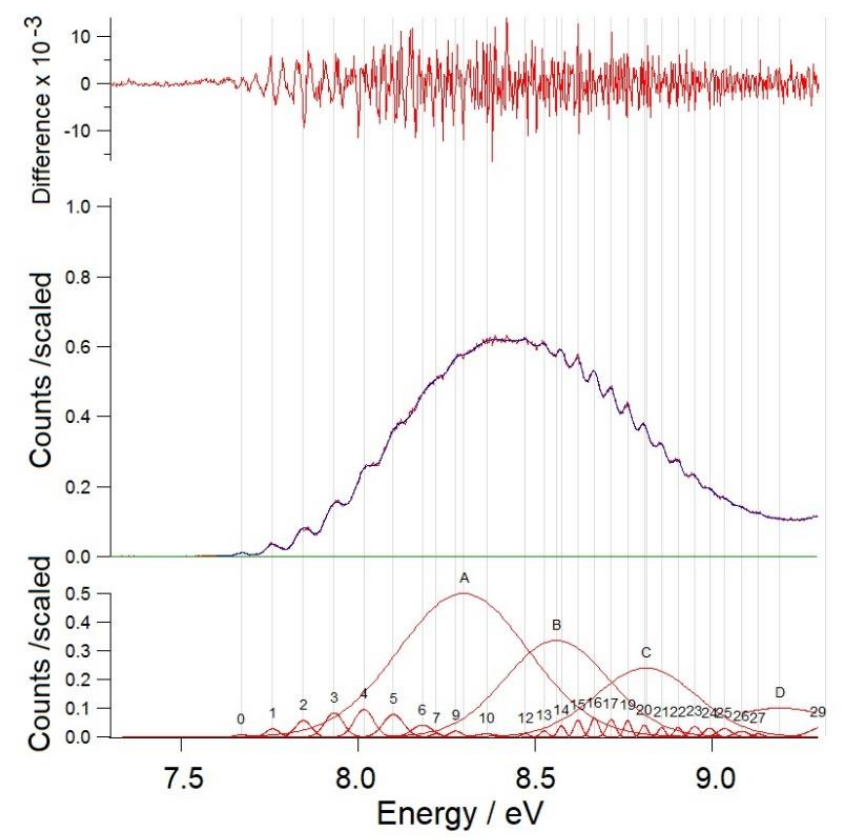

C. Theoretical methods. Our methods have specific uses and no single suite can lead us to a complete analysis. As in our COT and CHT studies, ${ }^{1-4}$ we use several suites.

The equilibrium structures of the $\mathrm{X}^{1} \mathrm{~A}_{1}$ ground states for $\mathrm{NBD}$ and $\mathrm{QC}$, shown in the supplementary material under SM5 as scale diagrams, demonstrate the much more compact QC system, arising from the double cyclopropane structure. The atomic coordinates for NBD and QC at the CCSD(T) level are also shown in SM5.

1. Equilibrium structures of the ionic states. Both the GAUSSIAN-16 (G-16) ${ }^{38}$ and MOLPRO suites ${ }^{39-42}$ were used to determine the AIE and equilibrium structures for the lowest states of each symmetry. The most rigorous procedures adopted here, were $\operatorname{CCSD}(T)^{43,44}$ and MP4(SDQ). ${ }^{45-47}$ In contrast to the former method, wave-functions from the latter are readily processed for vibrational analysis by G-16, as described below.

Since these AIE procedures are impracticable for interpretation of the wide scan PES shown in Figure 2, our approach was to determine the VIE for many states, by means of calculations at the ground state $\left(\mathrm{X}^{1} \mathrm{~A}_{1}\right)$ structure, for each of NBD and QC. This broad-brush theoretical approach generates an overall picture of the PES ionic state energies, together with intensities, 
and was performed by two methods. States where direct ionization occurs from one of a selected set of DOMOs, were formerly termed Koopmans' Theorem states (KT) which defines $\mathrm{IE}_{\mathrm{i}}=-\varepsilon_{\mathrm{i}}$ where $\varepsilon_{\mathrm{i}}$ is the orbital energy; this was widely used in early literature on NBD and QC. At higher energy, ionic states are accompanied by simultaneous electronic excitation, often referred to as 'shake-up' states. These have vacancies in two occupied orbitals, with one electron distributed between these, the spin between the singly occupied MOs can be either singlet or triplet.

Our most detailed wide scan theoretical approach uses the Tamm-Dancoff approximation (TDA), ${ }^{48,49}$ as implemented in GAMESS-UK. ${ }^{50}$ It is a single excitation, configuration interaction (CIS) procedure. The CI space was set at 63 active MOs and excludes the 7 core molecular orbitals (MOs) in $\mathrm{C}_{2 \mathrm{v}}$ symmetry; it is discussed further below.

We have also been able to determine the adiabatic ionization energies for both NBD and QC in the first (lowest excitation energy) states of each symmetry, by using the MP4(SDQ) method. These are also shown below.

2. Vibrational features of the ionic states. The equilibrium structures determined at the MP2 level were processed by the Pisa Group software, ${ }^{51-53}$ as implemented in G-16.

3. Basis sets. Those used varied with the nature of the calculation in progress, but all were at least triple zeta valence with polarisation (TZVP) ${ }^{56} 6-311+\mathrm{G}[2 \mathrm{~d}, 1 \mathrm{p}]{ }^{57}$ and Def2-TZVPPD. ${ }^{58}$ The equilibrium strucutres were determined using the TZVP and Def2-TZVPPD bases, including the calculations using the $\operatorname{CCSD}(\mathrm{T})$ method. The ionic state calculations, including those where vibrational analysis occurred, were at the TZVP level, since our related studies reported previously showed this to be adequate. Our present analyses shown in Sections III.C and III.D below also support this view.

4. NMR Chemical shifts. The shielding tensors and the corresponding spin coupling constants were computed with the Gauge-Independent Atomic Orbital (GIAO) method. ${ }^{54,55}$ Various 
studies $^{54,55}$ have pointed to the success of the Becke-Lee-Yang-Parr (B3LYP) functional, relative to other density functionals, for the calculation of spin-spin constants in NMR. We have tried several functionals, as shown in the supplementary material, which confirm that B3LYP seems particularly suitable for this purpose.

5. NMR bases. It became clear that to obtain calculated coupling constants close to experiment, the basis sets should have at least double polarization functions on a triple zeta valence basis set (TZVP); this is normally termed TZ2P. One specifically designed for the prediction of hyperfine coupling tensors of electron paramagnetic resonance (EPR-III) is included, ${ }^{59,60}$ it is a triple-zeta basis set including diffuse functions, double d-polarizations and a single set of f-polarization functions. In addition, the s-functions $(6,2)$ are contracted to $[4,2]$ for $\mathrm{H}$, and $(11,7,2,1) /[7,4,2,1]$ for $\mathrm{C}$; this results in an improved description close to the nuclei. At the Hartree-Fock level, the $\mathrm{X}^{1} \mathrm{~A}_{1}$ state doubly occupied orbitals (DOMOs) in $\mathrm{C}_{2} \mathrm{~V}$ symmetry differ; these are NBD: [10a $\left.1,6 b_{1}, 6 b_{2}, 3 a_{2}\right]$ and QC: [10a1, $\left.5 b_{1}, 7 b_{2}, 3 a_{2}\right]$.

\section{RESULTS}

\section{A. Comparison of the molecular structures of NBD and QC with experimental}

microwave and other spectral data. Several electron diffraction (ED), ${ }^{61-63}$ nematic phase nuclear magnetic resonance (NP-NMR) ${ }^{64-66}$ and microwave spectroscopy (MW) papers, ${ }^{67-69}$ have focused on NBD with few on QC..$^{70,71}$ Our theoretical comparisons with these experimental values are generally excellent, which give confidence in the overall theoretical analysis of NBD and QC. Since these results are not central to this study on ionic states, we defer these results to an Appendix, which shows a comparison of the bond lengths, rotational constants (RC) and quartic centrifugal distortion constants (QCDC) for neutral NBD in its MW substitution structure, ${ }^{68}$ with the present equilibrium structural theoretical values; the latter 
were determined at both the $\operatorname{CCSD}(\mathrm{T})$ and MP4(SDQ) levels, as shown in the Appendix Tables APP.I and APP.II.

We find the $\operatorname{CCSD}(\mathrm{T})$ energy difference, NBD-QC, at their respective equilibrium structures is: $-1.014 \mathrm{eV}$, close to previous calculated values ${ }^{24,72}(-1.023$ and $-1.032 \mathrm{eV}$ respectively) and experiment. $^{73}$

We use theoretical harmonic frequencies for both NBD and QC considerably in the analyses of the ionic states below. For brevity, we limit these to a1 modes, since these are the only vibrationally active modes present in the PES analyses; full lists of the frequencies, including their variation with ionic state symmetry, is given in the supplementary material as SM6. and can be compared with combined infrared and Raman spectral data for gas, liquid and polycrystalline phases. ${ }^{74}$

The ionic state RC values determined at the MP4(SDQ) level in Tables APP.I and APP.II, show some variation with electronic state. For all the $\mathrm{C}_{2 \mathrm{v}}$ states of $\mathrm{NBD}$ except ${ }^{2} \mathrm{~A}_{2}$, the double bonds are still apparent; but for the other symmetry states, there is lengthening of bonds, with weakening the $\mathrm{CH}_{2}$ bridge $\left({ }^{2} \mathrm{~A}_{1}\right.$ and $\left.{ }^{2} \mathrm{~B}_{2}\right)$, and for breaking the $\mathrm{C}=\mathrm{C}$ bonds $\left({ }^{2} \mathrm{~A}_{2}\right.$ state). Further details of the structures are given in the supplementary material as SM4. The nodal surfaces for the lowest AIE states of each symmetry are shown in Figure 6.

Figure 6. The highest occupied MOs for NBD and QC with differing sequences by symmetry of the occupied MOs 22 to 25 (HOMO). There is considerable similarity in appearance of the electron distribution in both compounds for the $a_{1}$ and $a_{2}$ symmetry MOs. 


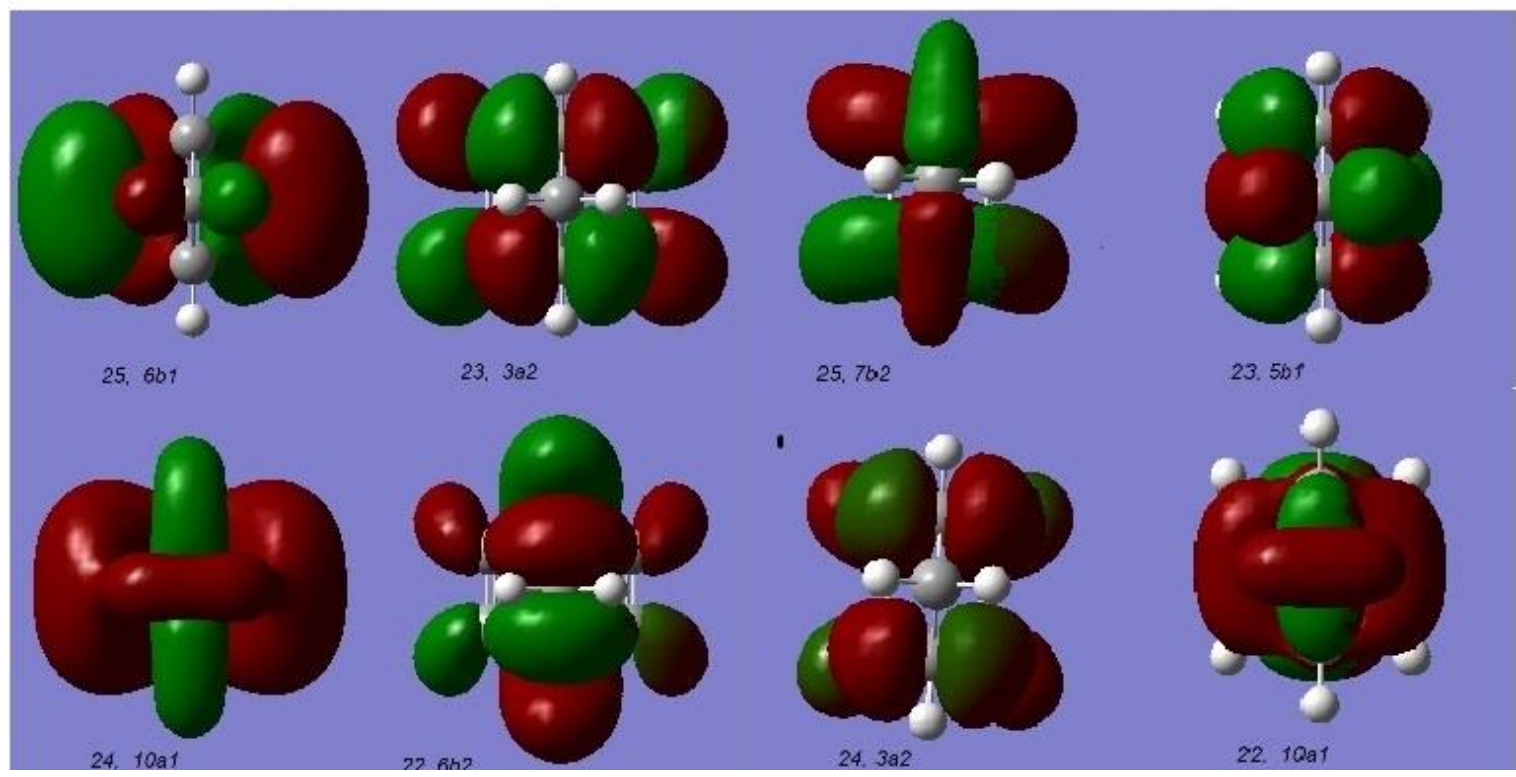

B. Reinterpretation of the ${ }^{1} \mathbf{H}$ NMR spectra of QC and NBD. Our experimental spectra for QC are shown in Figures 7A to 7C, with simulations in Figures 7D to 7F; the numerical results are summarized in Table I. The appearance of the QC spectrum, is critically dependent upon the ratio $\left(\delta_{\mathrm{ab}} / \mathrm{J}_{\mathrm{ab}}\right)$ of coupling constant $\left(\mathrm{J}_{\mathrm{ab}}\right)$ to chemical shift $(\delta)$ between a and b. The QC spectra are particularly complex at previously studied frequencies of 60 and 100 $\mathrm{MHz} ;{ }^{34,36,37}$ since the nuclei have similar shifts. A previous treatment as an $\mathrm{AB}_{2} \mathrm{X}_{2}$ spectrum, ${ }^{34}$ where A and B were effectively degenerate, gave the spectrum as a (uneven) 1:2:1-triplet (A) and a single dominant line with numerous weak bands $\left(\mathrm{B}_{2}\right) \cdot{ }^{34}$ At $300 \mathrm{MHz}$, the ${ }^{1} \mathrm{H} \mathrm{NMR}$ spectrum for $\mathrm{QC}$, shows that the multiplicity for the tertiary $\mathrm{H}$-atoms $\left(\mathrm{C}_{1} \mathrm{H} / \mathrm{C}_{4} \mathrm{H}\right)$, is clearly larger than the limiting triple-triplet coupling expected for a $1^{\text {st }}$ order analysis. Similarly, the uneven intensity of the triplet peaks, notionally 1:2:1 in intensity, also provides evidence that $2^{\text {nd }}$ order effects are still present. Our results for NBD at this level agree with previous analyses, its spectra are omitted. ${ }^{31}$

We have performed a theoretical analysis using the GIAO approach ${ }^{56,57}$ and obtained theoretical chemical shifts and coupling constants for QC. These analyses use an $\mathrm{AA}^{\prime} \mathrm{BB}^{\prime} \mathrm{CC}^{\prime} \mathrm{XX}^{\prime}$, approach where all ${ }^{1} \mathrm{H}$-nuclei are coupled; $\mathrm{XX}^{\prime}$ are designated as the $7-\mathrm{CH}_{2}$ 
unit, because of the larger difference $(0.53 \mathrm{ppm})$ from the other bands which are separated by only $0.13 \mathrm{ppm}$. Thus $2^{\text {nd }}$ order spin couplings between chemically equivalent, but magnetically non-equivalent atoms (isochronous nuclei), ${ }^{31}$ are included. A summary of the comparisons between the experimental NMR results ${ }^{36,37,71,75}$ is given in Table I; the theoretical analyses are given in Tables II and III; $\mathrm{H}$-atoms are labelled as the attached $\mathrm{C}$-atom. The spin-coupling and chemical shift parameters used in the simulated spectra, Figures 7D, 7E and 7F, reproduce the earlier 60 and $100 \mathrm{MHz}$ spectra satisfactorily. Full arrays for these couplings, together with those for NBD, are shown in the supplementary material at SM2. A subset of the full analysis of the chemical shift and spin coupling constant theoretical analyses is shown in Table I, with additional data in the supplementary material as SM2.

The present calculated chemical shifts for QC, shown in Tables I and II, are in almost exact agreement with those from two ${ }^{2} \mathrm{H}$ and ${ }^{13} \mathrm{C}$ 2-dimensional Q-COSY spectral determinations. ${ }^{71,75}$ The (1-bond) ${ }^{1} \mathrm{~J}^{13} \mathrm{C}^{1} \mathrm{H}$ spin couplings are very dependent upon both the basis set and the methodology; our best values (unscaled) are within 5\% of experiment. Secondorder polarization propagator approximations $(\mathrm{SOPPA})^{76,77}$ give even closer values, when compared with experiment. Our ${ }^{1} \mathrm{~J}^{13} \mathrm{C}^{1} \mathrm{H}$ values reflect the relative experimental magnitudes, $\mathrm{C}_{2} \mathrm{H}>\mathrm{C}_{1} \mathrm{H}>\mathrm{C}_{7} \mathrm{H}$, as observed. The vicinal ${ }^{1} \mathrm{H}-{ }^{1} \mathrm{H}$ couplings $\mathrm{J}_{1,2}$ and $\mathrm{J}_{2,3}$ are close to experiment, but $\mathbf{J}_{2,5}$ and $\mathbf{J}_{2,7}$ have not been identified previously; our values are shown in Table III. The calculated ${ }^{1} \mathrm{H}-{ }^{1} \mathrm{H}$ couplings values over 2- and 4-bonds $\left({ }^{2} \mathrm{~J}\right.$ and $\left.{ }^{4} \mathrm{~J}\right)$ are all found to be negative, and none are close to zero. Thus attempts at a $1^{\text {st }}$ order analysis are of no value for QC.

Table I. 300MHz ${ }^{1} \mathrm{H}$ NMR spectral chemical shifts (ppm) and coupling constants $(\mathrm{Hz})$ for both NBD and QC. The only directly comparable environments between NBD and QC are the couplings $J_{1,7}$ and $J_{4,7}$ where the values are similar.

\begin{tabular}{ccc}
\hline & NBD & QC (present) \\
\hline$\delta(1,4)$ & 3.57 & $1.360(2)$ \\
$\delta(2,3,5,6)$ & 6.76 & $1.490(2)$ \\
$\delta(7)$ & 1.98 & $2.020(2)$
\end{tabular}




$\begin{array}{rlrl}{ }^{3} J_{1,7} & ={ }^{3} J_{4,7} & 1.5 & 1.5 \\ { }^{3} J_{1,2}={ }^{3} J_{3,4} & ={ }^{3} J_{4,5}={ }^{3} J_{1,6} & 2.7 & 4.3 \\ { }^{3} J_{2,3} & ={ }^{3} J_{5,6} & 5.0 & 2.5 \\ { }^{3} J_{2,6} & ={ }^{3} J_{3,5} & 0 & 5.0 \\ { }^{4} J_{1,3}={ }^{4} J_{2,4} & ={ }^{4} J_{4,6}={ }^{4} J_{1,5} & 1.0 & 0\end{array}$

Table II. H- and C-nuclei chemical shift for both QC and NBD calculated by the GIAO method compared with experimental results. The magnetic shielding values are relative to tetramethyl silane (TMS) using the same basis set at its equilibrium geometry. For results from other procedures see the supplementary material, where the APFD results are corrected by $0.07 \mathrm{ppm}$, using our new TMS data as reference nucleus.

\begin{tabular}{|l|l|l|l|l|}
\hline QC & Method/Centres & $\mathbf{H 1 , 4}$ & $\mathbf{H 2 , 3 , 5 , 6}$ & $\mathbf{H 7}$ \\
\hline & Present NMR & 1.360 & 1.490 & 2.020 \\
\hline & B3LYP/EPR-III & 1.33 & 1.53 & 2.17 \\
\hline & & $\mathbf{C 1 , 4}$ & $\mathbf{C 2 , 3 , 5 , 6}$ & $\mathbf{C 7}$ \\
\hline & NMR $^{35,36}$ & $23.04^{35,36}$ & $14.77^{35,36}$ & $32.03^{35,36}$ \\
\hline & Q-COSY 2D NMR $^{71}$ & 22.6 & 14.4 & 31.6 \\
\hline & B3LYP/EPR-III & 29.08 & 19.24 & 38.80 \\
\hline$\delta$ from TMS/ppm & Method/Centres & $\mathbf{H 1 , 4}$ & $\mathbf{H 2 , 3 , 5 , 6}$ & $\mathbf{H 7}$ \\
\hline & Present + NMR & 3.57 & 6.76 & 1.98 \\
\hline & B3LYP/EPR-III & 3.69 & 7.28 & 2.24 \\
\hline & & $\mathbf{C 1 / 2}$ & $\mathbf{C 3 / 4 / 5 / 6}$ & $\mathbf{C 7}$ \\
\hline & Present NMR & 50.215 & 143.37 & 75.28 \\
\hline & NMR & 50.27 & 143.42 & 75.33 \\
\hline & B3LYP/EPR-III & 50.78 & 159.30 & 87.25 \\
\hline
\end{tabular}

Table III. ${ }^{1} \mathrm{H}^{1} \mathrm{H},{ }^{13} \mathrm{C}^{1} \mathrm{H}$ and ${ }^{13} \mathrm{C}^{13} \mathrm{Cspin}$ coupling constants for $\mathrm{QC}$ determined by using B3LYP with the EPR-III GIAO method. These are the only unique values, and the chemically equivalent but magnetically non-equivalent values are numerically the same. For results from other procedures see the supplementary material.

\begin{tabular}{|c|c|c|c|c|c|}
\hline \multicolumn{3}{|c|}{${ }^{13} \mathrm{C}-{ }^{1} \mathrm{H}$ couplings } & \multicolumn{3}{|c|}{${ }^{1} \mathrm{H}-{ }^{1} \mathrm{H}$ couplings } \\
\hline Centre & $\begin{array}{l}\text { B3LYP;E } \\
\text { PR-III }\end{array}$ & Expt & Centre & $\begin{array}{l}\text { B3LYP;EPR- } \\
\text { III }\end{array}$ & Expt \\
\hline $\mathrm{CH} 1$ & 170.00 & $165.9,{ }^{36} 166.0,{ }^{37}$ & $\mathrm{H} 1,4$ & 1.20 & \\
\hline $\mathrm{C} 1 \mathrm{H} 4$ & 9.63 & & $\mathrm{H} 1,2$ & 5.47 & 4.3 \\
\hline $\mathrm{C} 1 \mathrm{H} 2$ & -0.26 & & $\mathrm{H} 1,3$ & -0.62 & \\
\hline $\mathrm{C} 1 \mathrm{H} 3$ & 0.40 & & $\mathrm{H} 1,7$ & 1.63 & 1.5 \\
\hline $\mathrm{C} 1 \mathrm{H} 7$ & -2.56 & & $\mathrm{H} 2,3$ & 2.80 & 2.5 \\
\hline $\mathrm{C} 2 \mathrm{H} 1$ & 1.83 & & $\mathrm{H} 2,6$ & 6.50 & 5.0 \\
\hline $\mathrm{C} 2 \mathrm{H} 4$ & 3.65 & & $\mathrm{H} 2,5$ & 1.50 & \\
\hline $\mathrm{C} 2 \mathrm{H} 2$ & 189.22 & $183.2,{ }^{36} 184.7,{ }^{37}$ & $\mathrm{H} 2,7 \mathrm{a}$ & -0.34 & \\
\hline $\mathrm{C} 2 \mathrm{H} 3$ & 3.94 & & $\mathrm{H} 2,7 \mathrm{~b}$ & -0.34 & \\
\hline $\mathrm{C} 2 \mathrm{H} 6$ & -2.50 & & $\mathrm{H} 7 \mathrm{a}, 7 \mathrm{~b}$ & -11.10 & \\
\hline $\mathrm{C} 2 \mathrm{H} 5$ & 2.71 & & & & \\
\hline $\mathrm{C} 2 \mathrm{H} 7 \mathrm{a}$ & 0.67 & & & & \\
\hline $\mathrm{C} 2 \mathrm{H} 7 \mathrm{~b}$ & 7.71 & & & & \\
\hline $\mathrm{C} 7 \mathrm{H} 7$ & 133.95 & $132.2,{ }^{36} 131.4 .{ }^{37}$ & & & \\
\hline
\end{tabular}


Figure 7. The ${ }^{1} \mathrm{H}$ NMR spectral bands of quadricyclane at $300 \mathrm{MHz}(\mathrm{A}, \mathrm{B}, \mathrm{C})$ with the simulations (D, E, F) produced by the assigned coupling constants.

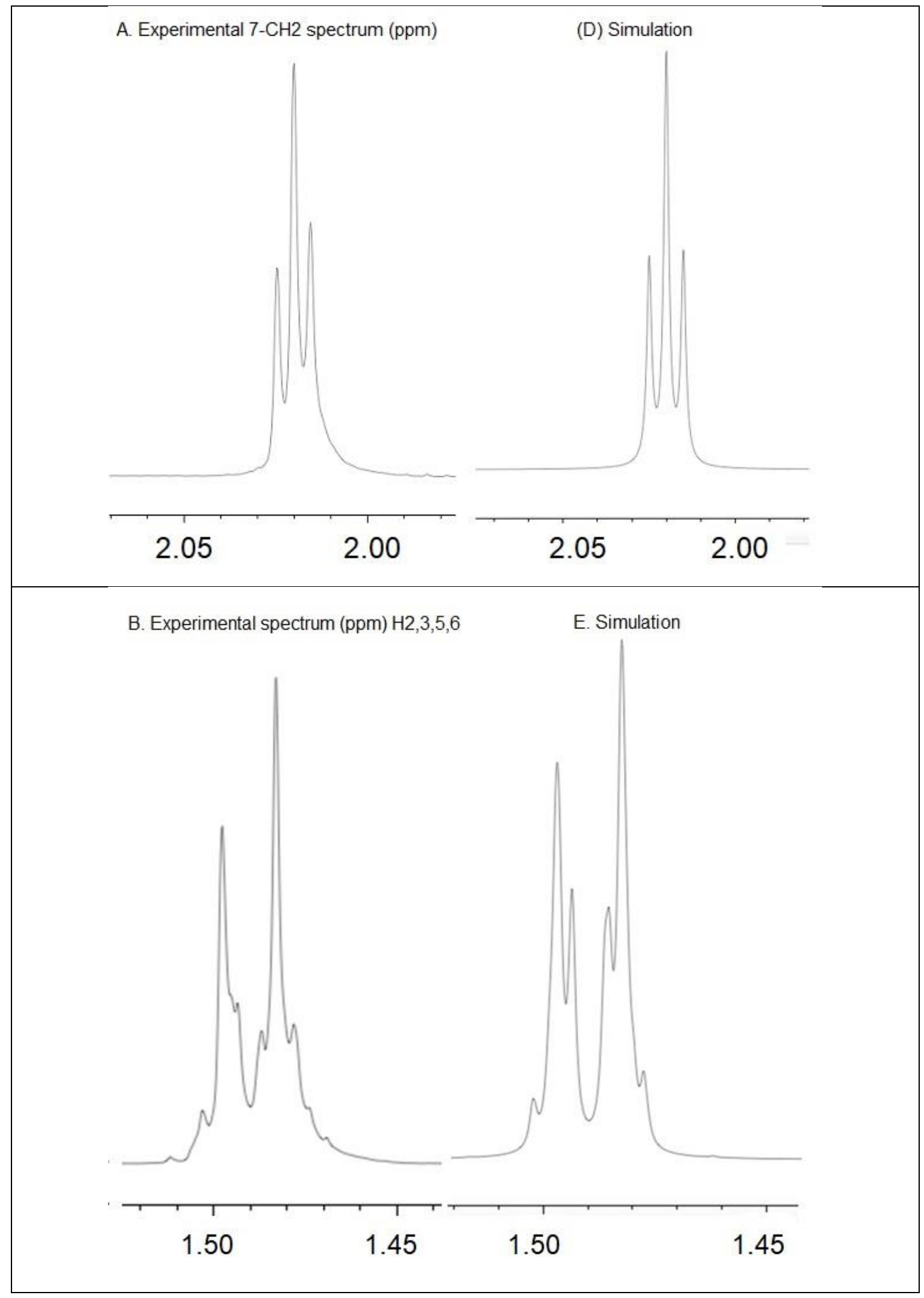




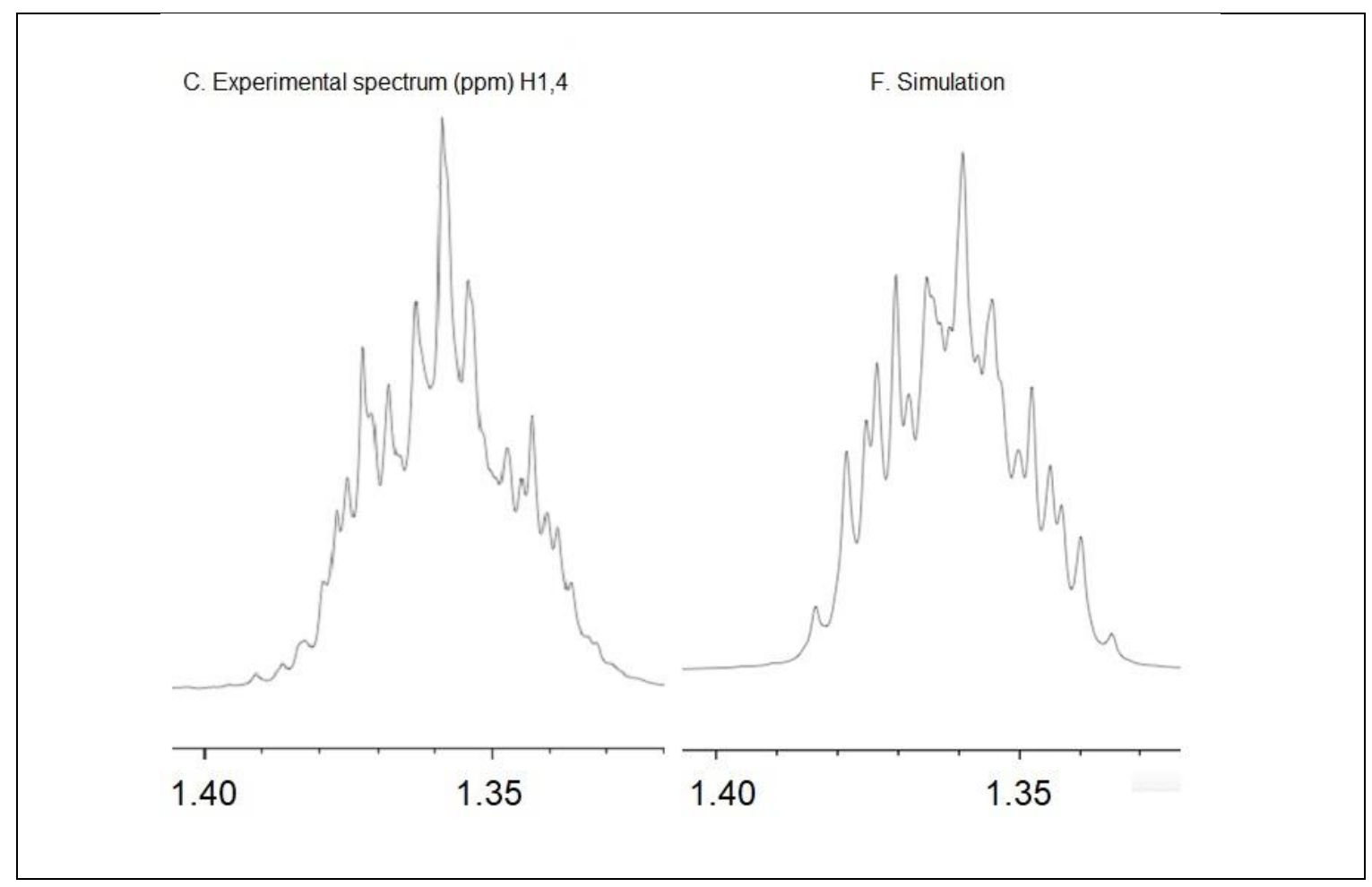

\section{C.The wide scan PES of NBD and QC. (1) Comparison with the theoretical study. The} new wide scan spectra, shown in Figures 8 and 9, have the scaled TDA energies and pole strength intensities superimposed in red; the AIE determined from the MP4(SDQ) calculations are shown in blue. These calculated sets of AIE and VIE for both compounds are close to the experimental peak onsets and maxima respectively, as expected. The corresponding unscaled TDA energies for the lower group of PES bands for both compounds are shown in Tables IV and V.

(2) Assignment of the PES bands. The two lowest IE of NBD at 8.69 and $9.55 \mathrm{eV}^{18-21}$ dominated early interest in the spectrum, since these previously assigned to $\pi$-ionizations, were attributed to the symmetric $\left(\pi^{+}\right)$and antisymmetric $\left(\pi^{-}\right)$combinations of the two $\pi$-orbitals with the IE order: ${ }^{2} \mathrm{~B}_{2}\left(\pi^{-}\right)<{ }^{2} \mathrm{~A}_{1}\left(\pi^{+}\right)$. Although this was attributed to through-space interactions being more important than through-bond interactions, ${ }^{18}$ this is the natural energy order owing to the presence of a node in the anti-symmetric combination. ${ }^{78-80}$ Although the TDA calculations for both NBD and QC suggest an almost identical lowest VIE there is little doubt that the QC PES 
shows the lower experimental AIE onset; we attribute this to extra $\sigma$-bond strain introduced by the double cyclopropane system of QC, some of which is released upon ionization.

Several attempts to assign symmetry to higher VIE for NBD have been made, but with little success. Thus the asymmetry parameter $(\beta)$ in PES angular distribution studies of NBD for these two ionic states, was found to be 1.04(1) and $0.94(1)$ for ${ }^{2} \mathrm{~B}_{2}$ and ${ }^{2} \mathrm{~A}_{1}$ states respectively; ${ }^{81,82}$ but does not confirm these two symmetry assignments. Similarly irradiation of NBD with $\mathrm{He}^{*}\left(2^{3} \mathrm{~S}\right.$ state at $\left.19.82 \mathrm{eV}\right)$, termed Penning ionization electron spectra (PIES), ${ }^{20}$ showed that the $2^{\text {nd }}$ and $4^{\text {th }}$ IEs are more intense than the $1^{\text {st }}$ and $3^{\text {rd }}$ under PIES relative to direct $\mathrm{He}(\mathrm{I})(27.211 \mathrm{eV})$ irradiation; but again this did not lead to experimental identification of any ionic state symmetries. However, both $\mathrm{IE}_{1}$ and $\mathrm{IE}_{2}$ under PIES showed broad shoulders relating to vibrational structure which was absent on both the $\mathrm{He}(\mathrm{I})$ and $\mathrm{He}(\mathrm{II})(40.78 \mathrm{eV})$ spectra. ${ }^{20}$ Although the $3^{\text {rd }}$ and higher IE of NBD and all of those for QC will relate to $\sigma$-ionization, interpretation of the principal band groupings in the envelope, and their states, is important. Lindholm et al ${ }^{19}$ presented the first wide energy range study of the NBD PES using a semiempirical procedure known as the Spectroscopic Potentials adjusted Intermediate Neglect of Differential Overlap (SPINDO). This analysis ${ }^{19}$ and that for another closely related method also showed an acceptable interpretation of the experimental groupings of IE; some unpublished details of it $^{19}$ (known as HAM3) are reported by Von Niessen et al. ${ }^{83}$ Later results by small scale singles and doubles configuration interaction (CISD) studies, ${ }^{84}$ and also Green's function (single excitation (CIS) studies) ${ }^{83}$ gave a similar level of agreement with the observed PES. In all cases the lowest 4 IE were: ${ }^{2} \mathrm{~B}_{1}<{ }^{2} \mathrm{~A}_{1}<{ }^{2} \mathrm{~A}_{2}<{ }^{2} \mathrm{~B}_{2}$.

There are many less studies of the QC PES ${ }^{85,86}$ and the previous assignment is based upon a Modified Intermediate Neglect of Differential Overlap (MINDO) calculation; the lowest IE for QC using MINDO were: ${ }^{2} \mathrm{~B}_{2}<{ }^{2} \mathrm{~A}_{2}<{ }^{2} \mathrm{~B}_{1}<{ }^{2} \mathrm{~A}_{1}$. 
The TDA results in Tables IV and V give a very close fit to the observed PES for both NBD and QC. Although these show different ionic state sequences by symmetry, both assignments show significant agreement with KT predictions. The PES analysis in Tables IV and V, shows 13 ionic states for NBD where the loss of electronic charge density on ionization is almost entirely confined to a single configuration; this is much higher than for $\mathrm{QC}$, where only 8 ionic states have a high pole strength (intensity) over 0.8 . Both indicate that ionization proceeds without major structural change; the low reorganization energy probably arises from the rigidity of these cage-like structures. The NBD and QC difference is a direct result of the $\pi$ electron system in NBD where many of the shake-up states have $\pi \pi^{*}$ excitations accompanying the ionization. For QC, where $\pi$-electrons are absent, the corresponding $\sigma \sigma^{*}$ excitations occur at significantly higher energies.

Table IV. The TDA analysis of the ionic states of NBD used for assignment of the NBD photoelectron spectrum. The ionic populations of the vacated MOs are spread over several ionic states at higher energy; only poles greater than 0.02 are shown.

\begin{tabular}{|c|c|c|c|c|c|c|c|}
\hline Energy & Symmetry & $\begin{array}{c}\text { Pole } \\
\text { strength }\end{array}$ & $\begin{array}{l}\text { Orbital } \\
\text { vacated }\end{array}$ & Energy & Symmetry & $\begin{array}{c}\text { Pole } \\
\text { strength }\end{array}$ & $\begin{array}{l}\text { Orbital } \\
\text { vacated }\end{array}$ \\
\hline 8.199 & ${ }^{2} \mathrm{~B}_{1}$ & 0.9032 & $5 b_{1}{ }^{-1}$ & 17.395 & ${ }^{2} \mathrm{~A}_{1}$ & 0.7409 & $4 a_{1}^{-1}$ \\
\hline 9.224 & ${ }^{2} \mathrm{~A}_{1}$ & 0.9019 & $7 a^{-1}$ & 17.783 & ${ }^{2} \mathrm{~A}_{2}$ & 0.0600 & $1 \mathrm{a} 2^{-1}$ \\
\hline 11.434 & ${ }^{2} \mathrm{~A}_{2}$ & 0.8971 & $2 \mathrm{a}^{-1}$ & 18.564 & ${ }^{2} \mathrm{~A}_{2}$ & 0.2025 & $1 \mathrm{a} 2^{-1}$ \\
\hline 11.550 & ${ }^{2} \mathrm{~B}_{2}$ & 0.9015 & $4 b_{2} 2^{-1}$ & 18.714 & ${ }^{2} \mathrm{~A}_{2}$ & 0.4434 & $1 \mathrm{a}^{-1}$ \\
\hline 12.178 & ${ }^{2} \mathrm{~B}_{1}$ & 0.9011 & $4 b_{1}^{-1}$ & 19.025 & ${ }^{2} \mathrm{~A}_{1}$ & 0.2275 & $3 a_{1}^{-1}$ \\
\hline 12.564 & ${ }^{2} \mathrm{~B}_{2}$ & 0.1671 & $3 b_{2} 2^{-1}$ & 19.071 & ${ }^{2} \mathrm{~A}_{1}$ & 0.4243 & $2 \mathrm{a} 1^{-1}$ \\
\hline 12.815 & ${ }^{2} \mathrm{~A}_{1}$ & 0.8796 & $6 a^{-1}$ & 19.210 & ${ }^{2} \mathrm{~A}_{2}$ & 0.0227 & $1 \mathrm{a} 2^{-1}$ \\
\hline 12.832 & ${ }^{2} \mathrm{~B}_{2}$ & 0.7357 & $3 b_{2} 2^{-1}$ & 19.471 & ${ }^{2} \mathrm{~A}_{2}$ & 0.0244 & $1 \mathrm{a}^{-1}$ \\
\hline 13.239 & ${ }^{2} \mathrm{~A}_{1}$ & 0.8568 & $5 a^{-1}$ & 22.695 & ${ }^{2} \mathrm{~A}_{1}$ & 0.2888 & $1 \mathrm{a}^{-1}$ \\
\hline 14.286 & ${ }^{2} \mathrm{~B}_{1}$ & 0.8873 & $3 b_{1}^{-1}$ & 23.023 & ${ }^{2} \mathrm{~B}_{2}$ & 0.0404 & $1 b_{2}{ }^{-1}$ \\
\hline 15.986 & ${ }^{2} \mathrm{~B}_{1}$ & 0.7284 & $2 b_{1}^{-1}$ & 23.241 & ${ }^{2} \mathrm{~B}_{2}$ & 0.0393 & $1 b_{2}{ }^{-1}$ \\
\hline 16.224 & ${ }^{2} \mathrm{~B}_{1}$ & 0.0642 & $2 b_{1}^{-1}$ & 23.483 & ${ }^{2} \mathrm{~B}_{2}$ & 0.0691 & $1 b_{2}{ }^{-1}$ \\
\hline 16.949 & ${ }^{2} \mathrm{~B}_{2}$ & 0.3388 & $2 \mathrm{~b}_{2}{ }^{-1}$ & 23.604 & ${ }^{2} \mathrm{~B}_{2}$ & 0.1374 & $1 b_{2} 2^{-1}$ \\
\hline 17.039 & ${ }^{2} \mathrm{~B}_{2}$ & 0.5046 & $2 b_{2}{ }^{-1}$ & 23.718 & ${ }^{2} \mathrm{~B}_{2}$ & 0.0468 & $1 b_{2}{ }^{-1}$ \\
\hline 17.187 & ${ }^{2} \mathrm{~B}_{1}$ & 0.0423 & $2 b_{1}^{-1}$ & 24.037 & ${ }^{2} \mathrm{~B}_{1}$ & 0.0408 & $1 b_{1}^{-1}$ \\
\hline
\end{tabular}

Table V. The TDA analysis of the ionic states of QC used for assignment of the QC photoelectron spectrum. The ionic populations of the vacated MOs are spread over several ionic states at higher energy; only poles greater than 0.02 are shown. All ${ }^{2} \mathrm{~A}_{2}$ shake-up states have very low intensity. 


\begin{tabular}{|c|c|c|c|c|c|c|c|}
\hline Energy & Symmetry & $\begin{array}{c}\text { Pole } \\
\text { strength }\end{array}$ & $\begin{array}{l}\text { Orbital } \\
\text { vacated }\end{array}$ & Energy & Symmetry & $\begin{array}{l}\text { Pole } \\
\text { strength }\end{array}$ & $\begin{array}{l}\text { Orbital } \\
\text { vacated }\end{array}$ \\
\hline 8.199 & ${ }^{2} \mathrm{~B}_{2}$ & 0.91945 & $7 b_{2}{ }^{-1}$ & 19.931 & ${ }^{2} \mathrm{~B}_{2}$ & 0.02611 & $3 b_{2}^{-1}$ \\
\hline 9.608 & ${ }^{2} \mathrm{~A}_{2}$ & 0.91719 & $3 a 2^{-1}$ & 20.897 & ${ }^{2} \mathrm{~B}_{1}$ & 0.18474 & $2 b_{1}^{-1}$ \\
\hline 9.946 & ${ }^{2} \mathrm{~B}_{1}$ & 0.91671 & $5 b_{1}^{-1}$ & 21.105 & ${ }^{2} \mathrm{~B}_{1}$ & 0.21036 & $2 b_{1}^{-1}$ \\
\hline 10.914 & ${ }^{2} \mathrm{~A}_{1}$ & 0.91119 & $10 \mathrm{a}_{1}^{-1}$ & 21.121 & ${ }^{2} \mathrm{~B}_{1}$ & 0.17168 & $2 b_{1}^{-1}$ \\
\hline 11.997 & ${ }^{2} \mathrm{~B}_{1}$ & 0.91301 & $4 b_{1}{ }^{-1}$ & 21.375 & ${ }^{2} \mathrm{~B}_{1}$ & 0.08938 & $2 b_{1}^{-1}$ \\
\hline 12.134 & ${ }^{2} \mathrm{~B}_{2}$ & 0.91287 & $6 b_{2}{ }^{-1}$ & 22.366 & ${ }^{2} \mathrm{~B}_{1}$ & 0.06289 & $2 b_{1}{ }^{-1}$ \\
\hline 13.440 & ${ }^{2} \mathrm{~A}_{1}$ & 0.90600 & $9 a_{1}^{-1}$ & 23.916 & ${ }^{2} \mathrm{~A}_{1}$ & 0.14551 & $5 a^{-1}$ \\
\hline 14.603 & ${ }^{2} \mathrm{~A}_{1}$ & 0.89966 & $8 a_{1}^{-1}$ & 24.032 & ${ }^{2} \mathrm{~A}_{1}$ & 0.16511 & $5 a_{1}^{-1}$ \\
\hline 14.861 & ${ }^{2} \mathrm{~B}_{1}$ & 0.90423 & $3 b_{1}^{-1}$ & 24.115 & ${ }^{2} \mathrm{~A}_{1}$ & 0.04246 & $5 a_{1}^{-1}$ \\
\hline 14.886 & ${ }^{2} \mathrm{~B}_{2}$ & 0.89918 & $5 b_{2} 2^{-1}$ & 25.007 & ${ }^{2} \mathrm{~B}_{2}$ & 0.03384 & $2 \mathrm{~b}_{2} 2^{-1}$ \\
\hline 17.680 & ${ }^{2} \mathrm{~A}_{2}$ & 0.86364 & $2 \mathrm{a}_{2}^{-1}$ & 25.077 & ${ }^{2} \mathrm{~A}_{1}$ & 0.03016 & $4 a_{1}^{-1}$ \\
\hline 17.916 & ${ }^{2} \mathrm{~A}_{1}$ & 0.85989 & $7 a_{1}^{-1}$ & 25.094 & ${ }^{2} \mathrm{~A}_{1}$ & 0.03436 & $4 a_{1}^{-1}$ \\
\hline 18.648 & ${ }^{2} \mathrm{~B}_{2}$ & 0.81202 & $4 \mathrm{~b}_{2}{ }^{-1}$ & 25.379 & ${ }^{2} \mathrm{~B}_{2}$ & 0.06445 & $2 b_{2}{ }^{-1}$ \\
\hline 19.005 & ${ }^{2} \mathrm{~A}_{1}$ & 0.73579 & $6 a_{1}^{-1}$ & 25.475 & ${ }^{2} \mathrm{~B}_{2}$ & 0.06498 & $2 b_{2}{ }^{-1}$ \\
\hline 19.445 & ${ }^{2} \mathrm{~A}_{1}$ & 0.11051 & $6 a_{1}^{-1}$ & 25.508 & ${ }^{2} \mathrm{~B}_{2}$ & 0.08387 & $2 \mathrm{~b}_{2}{ }^{-1}$ \\
\hline
\end{tabular}

Figure 8. The wide scan photoelectron spectrum of norbornadiene correlated with the TDA pole strengths (in red). The calculated energies have been fitted to the spectrum by means of a linear correlation where Ecorr $=0.912(13) * E_{T D A}+1.067(20)$ with adjacent $R^{2}$ correlation coefficient 0.998. The MP4(SDQ) AIE are shown above as blue vertical bars.

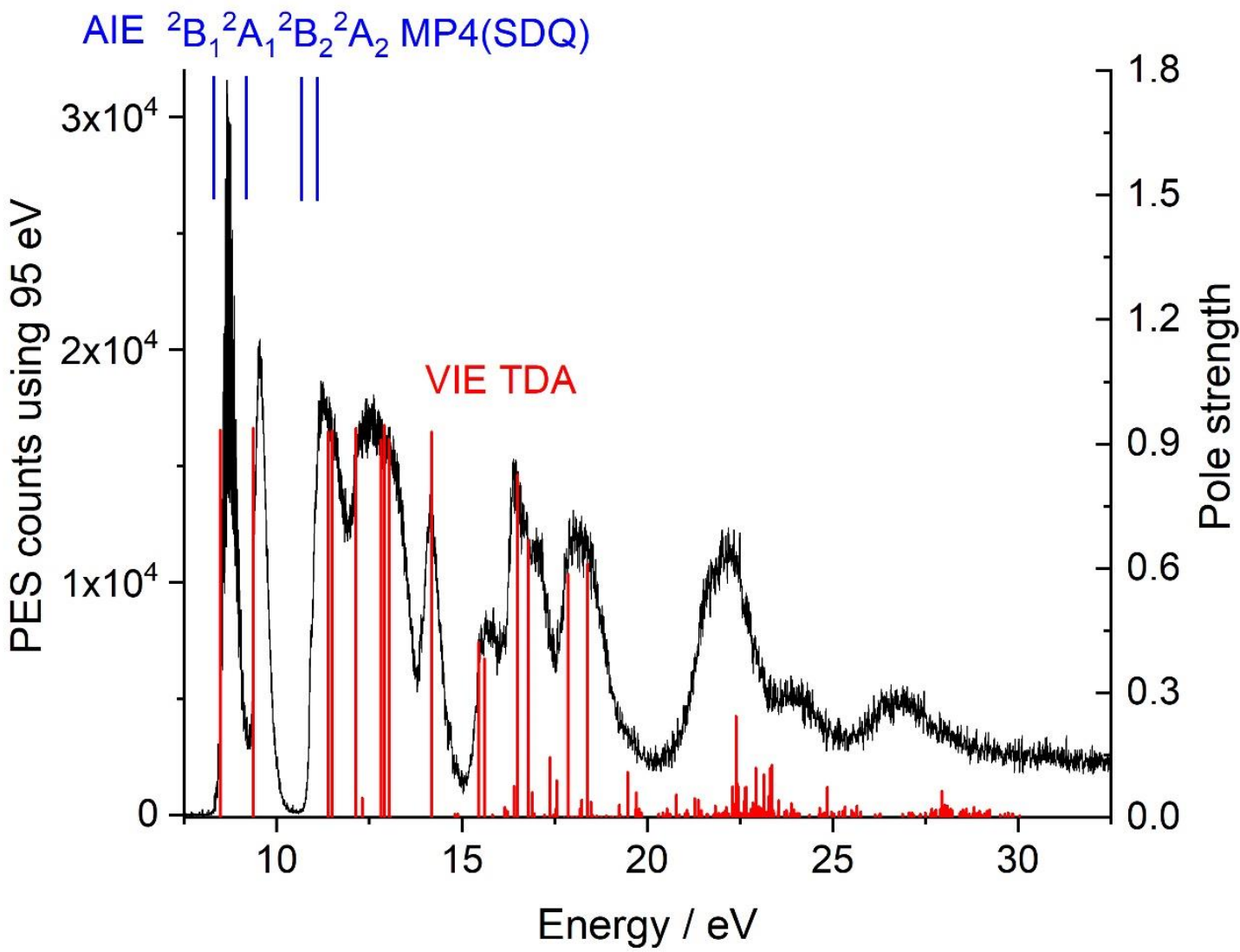


Figure 9. The wide scan photoelectron spectrum of quadricyclane correlated with the TDA pole strengths. The calculated energies shown in red have been fitted to the spectrum by means of a linear correlation of the energies where Ecorr $=0.887(15) * \mathbf{E}_{\mathrm{TDA}}$ +1.333 (20) with adjacent $R^{2}$ correlation coefficient 0.998 . The adiabatic ionization energies for the lowest states of each symmetry calculated by the MP4(SDQ) method are shown in blue.

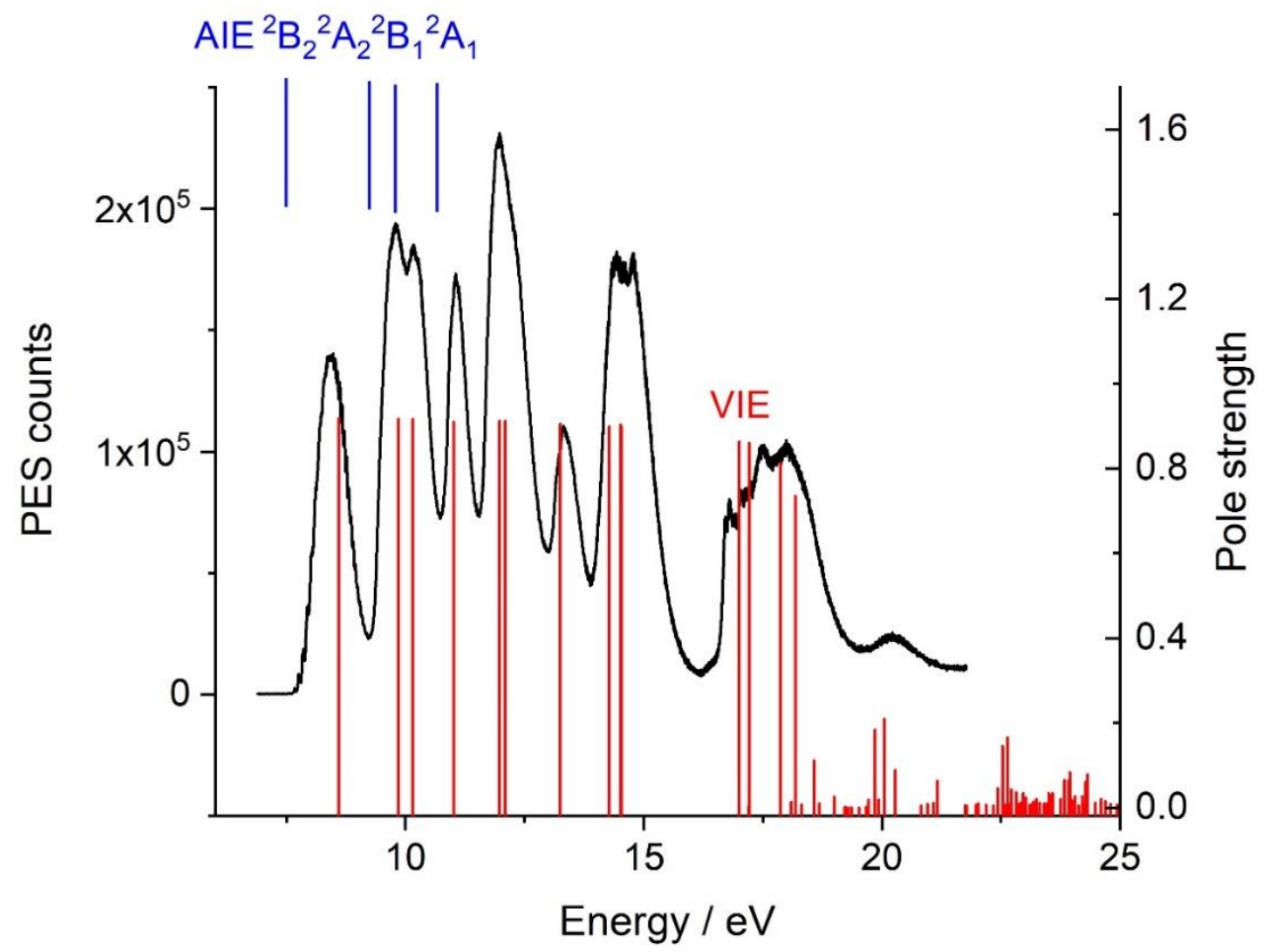

D.Vibrationally excited states. (1) Norbornadiene. All previous photoelectron studies of NBD and $\mathrm{QC}^{17-24}$ observed the lowest IE as a single band rather than the multiplet shown in Figure 3 for NBD, and in Figure 5 for QC. The adiabatic ionization energy ( $\mathrm{AIE}_{1}$ ) for NBD, assigned to the ${ }^{2} \mathrm{~B}_{1}$ state at $8.279 \mathrm{eV}$, shows this progression of 18 members, with decreasing vibration frequency from 392 to $340 \mathrm{~cm}^{-1}$; our calculated frequency for the ${ }^{2} \mathrm{~B}_{1}$ state at the MP4(SDQ) level is $381 \mathrm{~cm}^{-1}$. We correlate the Franck-Condon (FC) envelope of IE 1 with the NBD spectrum in Figure 3. The envelope becomes progressively more complex with increasing energy and a portion of this is shown in the supplementary material as Figure SM6. Only a vibrations contribute in this FC study and these are summarized in Tables VI and VII; other vibrations of $b_{1} b_{2}$ and $a_{2}$ symmetry are shown in the supplementary material as Table SM6. 
Table VI. The a harmonic frequencies including their sequence numbers for the ground and ionic states for norbornadiene determined at the TZVP level. The ${ }^{2} A_{1}$ calculation leads to a negative $b_{2}$ eigenvalue (mode 1). The Franck-Condon calculation is performed by projection out from the $\mathrm{X}^{1} \mathrm{~A}_{1}$ modes the one having largest overlap with the ionic state in the Duschinsky matrix. The full sequences are shown in the supplementary material as SM6. The modes labelled in ascending frequency are as used in the Franck-Condon profiles of active modes shown in Table VII.

\begin{tabular}{|c|c|c|c|c|}
\hline $\mathrm{X}^{1} \mathrm{~A}_{1}$ & ${ }^{2} \mathrm{~B}_{1}$ & ${ }^{2} \mathrm{~B}_{2}$ & ${ }^{2} \mathrm{~A}_{1}$ & ${ }^{2} \mathrm{~A}_{2}$ \\
\hline 1 & 2 & 3 & 2 & 4 \\
\hline 429 & 399 & 429 & 453 & 298 \\
\hline 7 & 7 & 7 & 5 & 8 \\
\hline 730 & 782 & 672 & 661 & 746 \\
\hline 8 & 8 & 8 & 8 & 12 \\
\hline 794 & 839 & 712 & 787 & 884 \\
\hline 11 & 11 & 10 & 9 & 14 \\
\hline 904 & 923 & 796 & 827 & 982 \\
\hline 16 & 15 & 18 & 15 & 15 \\
\hline 967 & 1013 & 969 & 964 & 1004 \\
\hline 20 & 19 & 21 & 20 & 22 \\
\hline 1138 & 1132 & 1110 & 1151 & 1227 \\
\hline 24 & 25 & 25 & 21 & 27 \\
\hline 1258 & 1292 & 1196 & 1187 & 1401 \\
\hline 29 & 28 & 28 & 27 & 29 \\
\hline 1513 & 1503 & 1483 & 1520 & 1633 \\
\hline 31 & 30 & 30 & 28 & 30 \\
\hline 1615 & 1537 & 1619 & 1563 & 1917 \\
\hline 32 & 32 & 33 & 30 & 31 \\
\hline 3096 & 3107 & 2951 & 3149 & 3237 \\
\hline 35 & 35 & 34 & 32 & 36 \\
\hline 3174 & 3221 & 3149 & 3210 & 3339 \\
\hline 39 & 38 & 39 & 37 & 38 \\
\hline 3277 & 3264 & 3289 & 3279 & 3369 \\
\hline
\end{tabular}

Table VII. Vibrationally excited ionic states of NBD. The modes excited shown here are the $a_{1}$ frequencies for the ionic state shown, together with the number (n) of quanta excited as '^n'. binary and higher combination bands are separated by semi-colons.

\begin{tabular}{|r|l|r|r|r|r|}
\hline \multicolumn{2}{|c|}{${ }^{2} \mathrm{~B}_{1}$} & \multicolumn{3}{c|}{${ }^{2} \mathrm{~A}_{1}$} \\
\hline $\begin{array}{c}\text { Energy } \\
\mathrm{cm}^{-1}\end{array}$ & $\begin{array}{c}\text { Modes excited } \\
+ \text { quanta } \\
\text { Energy of the 0-0 transition: } 8.2624 \mathrm{eV}\end{array}$ & $\begin{array}{c}\text { Relative } \\
\text { intensity }\end{array}$ & $\begin{array}{c}\text { Energy } \\
\mathrm{cm}^{-1}\end{array}$ & $\begin{array}{c}\text { Modes } \\
\text { Excited } \\
+ \text { quanta }\end{array}$ & $\begin{array}{c}\text { Relative } \\
\text { intensity }\end{array}$ \\
\hline \multicolumn{2}{|c|}{${ }^{\mathrm{a}}$} \\
\hline 0 & 0 & 820 & 0 & 0 & 6877 \\
\hline 399 & $2^{\wedge} 1$ & 4147 & 453 & $2^{\wedge} 1$ & 24060 \\
\hline 798 & $2^{\wedge} 2$ & 15900 & 661 & $5^{\wedge} 1$ & 4785 \\
\hline 1197 & $2^{\wedge} 3$ & 39500 & 905 & $2^{\wedge} 2$ & 56040 \\
\hline 1238 & $8^{\wedge} 1 ; 2^{\wedge} 1$ & 1949 & 1113 & $5^{\wedge} 1 ; 2^{\wedge} 1$ & 21160 \\
\hline
\end{tabular}




\begin{tabular}{|c|c|c|c|c|c|}
\hline 1596 & $2^{\wedge} 4$ & 71560 & 1358 & $2^{\wedge} 3$ & 59880 \\
\hline 1637 & $8^{\wedge} 1 ; 2^{\wedge} 2$ & 7166 & 1566 & $5^{\wedge} 1 ; 2^{\wedge} 2$ & 31830 \\
\hline 1995 & $2^{\wedge} 5$ & 100800 & 1604 & $20^{\wedge} 1 ; 2^{\wedge} 1$ & 3329 \\
\hline 2036 & $8^{\wedge} 1 ; 2^{\wedge} 3$ & 17060 & 1693 & $8^{\wedge} 1 ; 2^{\wedge} 2$ & 2380 \\
\hline 2210 & $15^{\wedge} 1 ; 2^{\wedge} 3$ & 2327 & 1732 & $9^{\wedge} 1 ; 2^{\wedge} 2$ & 3532 \\
\hline 2329 & $19^{\wedge} 1 ; 2^{\wedge} 3$ & 4911 & 1774 & $5^{\wedge} 2 ; 2^{\wedge} 1$ & 4893 \\
\hline 2335 & $30^{\wedge} 1 ; 2^{\wedge} 2$ & 5576 & 1811 & $2^{\wedge} 4$ & 73830 \\
\hline 2394 & $2^{\wedge} 6$ & 115000 & 2016 & $28^{\wedge} 1 ; 2^{\wedge} 1$ & 3467 \\
\hline 2435 & $8^{\wedge} 1 ; 2^{\wedge} 4$ & 29590 & 2019 & $5^{\wedge} 1 ; 2^{\wedge} 3$ & 49480 \\
\hline 2477 & $8^{\wedge} 2 ; 2^{\wedge} 2$ & 1969 & 2057 & $20^{\wedge} 1 ; 2^{\wedge} 2$ & 7067 \\
\hline \multicolumn{3}{|c|}{${ }^{2} \mathrm{~B}_{2}$} & \multicolumn{3}{|c|}{${ }^{2} \mathrm{~A}_{2}$} \\
\hline \multicolumn{3}{|c|}{ Energy of the $0-0$ transition $10.6887 \mathrm{eV}$} & \multicolumn{3}{|c|}{ Energy of the $0-0$ transition: $11.3739 \mathrm{eV}$} \\
\hline 0 & 0 & 729 & 0 & 0 & 3616 \\
\hline 1196 & $25^{\wedge} 1$ & 2717 & 746 & $7^{\wedge} 1$ & 7965 \\
\hline 1343 & $7^{\wedge} 2$ & 2066 & 1227 & $21^{\wedge} 1$ & 3274 \\
\hline 1868 & $25^{\wedge} 1 ; 7^{\wedge} 1$ & 8230 & 1492 & $7^{\wedge} 2$ & 7794 \\
\hline 2392 & $25^{\wedge} 2$ & 6302 & 1630 & $11^{\wedge} 1 ; 7^{\wedge} 1$ & 2706 \\
\hline 2540 & $25^{\wedge} 1 ; 7^{\wedge} 2$ & 11630 & 1728 & $13^{\wedge} 1 ; 7^{\wedge} 1$ & 4224 \\
\hline 2978 & $25^{\wedge} 1 ; 21^{\wedge} 1 ; 7^{\wedge} 1$ & 4932 & 1973 & $21^{\wedge} 1 ; 7^{\wedge} 1$ & 6423 \\
\hline 3064 & $25^{\wedge} 2 ; 7^{\wedge} 1$ & 18790 & 2238 & $7^{\wedge} 3$ & 4491 \\
\hline 3211 & $25^{\wedge} 1 ; 7^{\wedge} 3$ & 10150 & 2376 & $11^{\wedge} 1 ; 7^{\wedge} 2$ & 2383 \\
\hline 3336 & $25^{\wedge} 1 ; 10^{\wedge} 1 ; 7^{\wedge} 2$ & 2672 & 2474 & $13^{\wedge} 1 ; 7^{\wedge} 2$ & 6334 \\
\hline 3502 & $25^{\wedge} 2 ; 21^{\wedge} 1$ & 2688 & 2663 & $29^{\wedge} 1 ; 7^{\wedge} 1$ & 4833 \\
\hline 3589 & $25^{\wedge} 3$ & 7213 & 2719 & $21^{\wedge} 1 ; 7^{\wedge} 2$ & 5585 \\
\hline 3650 & $25^{\wedge} 1 ; 21^{\wedge} 1 ; 7^{\wedge} 2$ & 6613 & 2857 & $21^{\wedge} 1 ; 11^{\wedge} 1 ; 7^{\wedge} 1$ & 3295 \\
\hline 3736 & $25^{\wedge} 2 ; 7^{\wedge} 2$ & 16880 & 2955 & $21^{\wedge} 1 ; 13^{\wedge} 1 ; 7^{\wedge} 1$ & 5686 \\
\hline 3860 & $25^{\wedge} 2 ; 10^{\wedge} 1 ; 7^{\wedge} 1$ & 5025 & 3200 & $21^{\wedge} 2 ; 7^{\wedge} 1$ & 3613 \\
\hline 3883 & $25^{\wedge} 1 ; 7^{\wedge} 4$ & 6098 & 3220 & $13^{\wedge} 1 ; 7^{\wedge} 3$ & 3682 \\
\hline 4007 & $25^{\wedge} 1 ; 10^{\wedge} 1 ; 7^{\wedge} 3$ & 2440 & 3409 & $29^{\wedge} 1 ; 7^{\wedge} 2$ & 6804 \\
\hline 4033 & $25^{\wedge} 2 ; 18^{\wedge} 1 ; 7^{\wedge} 1$ & 2943 & 3465 & $21^{\wedge} 1 ; 7^{\wedge} 3$ & 5155 \\
\hline 4174 & $25^{\wedge} 2 ; 21^{\wedge} 1 ; 7^{\wedge} 1$ & 7845 & 3603 & $21^{\wedge} 1 ; 11^{\wedge} 1 ; 7^{\wedge} 2$ & 3244 \\
\hline 4260 & $25^{\wedge} 3 ; 7^{\wedge} 1$ & 21770 & 3644 & $29^{\wedge} 1 ; 13^{\wedge} 1 ; 7^{\wedge} 1$ & 4391 \\
\hline 4321 & $25^{\wedge} 1 ; 21^{\wedge} 1 ; 7^{\wedge} 3$ & 5451 & 3701 & $21^{\wedge} 1 ; 13^{\wedge} 1 ; 7^{\wedge} 2$ & 5010 \\
\hline 4408 & $25^{\wedge} 2 ; 7^{\wedge} 3$ & 14910 & 3890 & $29^{\wedge} 1 ; 21^{\wedge} 1 ; 7^{\wedge} 1$ & 5677 \\
\hline 4532 & $25^{\wedge} 2 ; 10^{\wedge} 1 ; 7^{\wedge} 2$ & 7299 & 3946 & $21^{\wedge} 2 ; 7^{\wedge} 2$ & 3508 \\
\hline 4699 & $25^{\wedge} 3 ; 21^{\wedge} 1$ & 4404 & 4155 & $29^{\wedge} 1 ; 7^{\wedge} 3$ & 4234 \\
\hline 4705 & $25^{\wedge} 2 ; 18^{\wedge} 1 ; 7^{\wedge} 2$ & 4311 & 4390 & $29^{\wedge} 1 ; 13^{\wedge} 1 ; 7^{\wedge} 2$ & 3743 \\
\hline 4785 & $25^{\wedge} 4$ & 8079 & 4447 & $21^{\wedge} 1 ; 13^{\wedge} 1 ; 7^{\wedge} 3$ & 2580 \\
\hline 4846 & $25^{\wedge} 2 ; 21^{\wedge} 1 ; 7^{\wedge} 2$ & 10640 & & & \\
\hline 4932 & $25^{\wedge} 3 ; 7^{\wedge} 2$ & 30650 & & & \\
\hline
\end{tabular}

\section{Footnotes to Table VII}

a Sequential with increasing frequency..

${ }^{b}$ Molar absorption coefficient $\mathrm{dm}^{3} \cdot \mathrm{mol}^{-1} \cdot \mathrm{cm}^{-1}$ 
(2.) Quadricyclane. We find the $\mathrm{AIE}_{1}$ for $\mathrm{QC}$ at $7.671 \mathrm{eV}$, and assign it to the ${ }^{2} \mathrm{~B}_{2}$ state. Our calculated vibration frequency for this state is $663 \mathrm{~cm}^{-1}$. A weak vibrational progression of 9 or more members, with vibration frequency decreasing from 703 to $660 \mathrm{~cm}^{-1}$ is evident on the leading edge of $\mathrm{IE}_{1}$ of QC in Figure 5, but with a clearly different vibrational separation from another series on the trailing edge. Thus the minor contamination of the QC sample by NBD, makes it clear that the 2 sets of vibrations are unrelated. We have enhanced the differences by peak fitting and subtracting broad Gaussian peaks from the $\mathrm{IE}_{1}$ band in Figure 5, and processing the resulting regular residuals from the subtraction, as seen in Figure 10. A summary of the calculated a vibration frequencies and leading terms in the Franck-Condon analyses for the ${ }^{2} \mathrm{~B}_{2}$ state, are given in Tables VIII and IX respectively.

The full Franck-Condon analysis is superimposed on the initial band of the QC PES in Figure 11. The calculated envelope gives a realistic account of the leading edge of the spectrum.

Figure 10. The resulting regular residuals after a best fit asymmetric gaussian function to the QC PES first band. The previously mentioned minor contamination of the sample by NBD is seen on the trailing edge with a quite different vibrational appearance occurring on the leading edge.

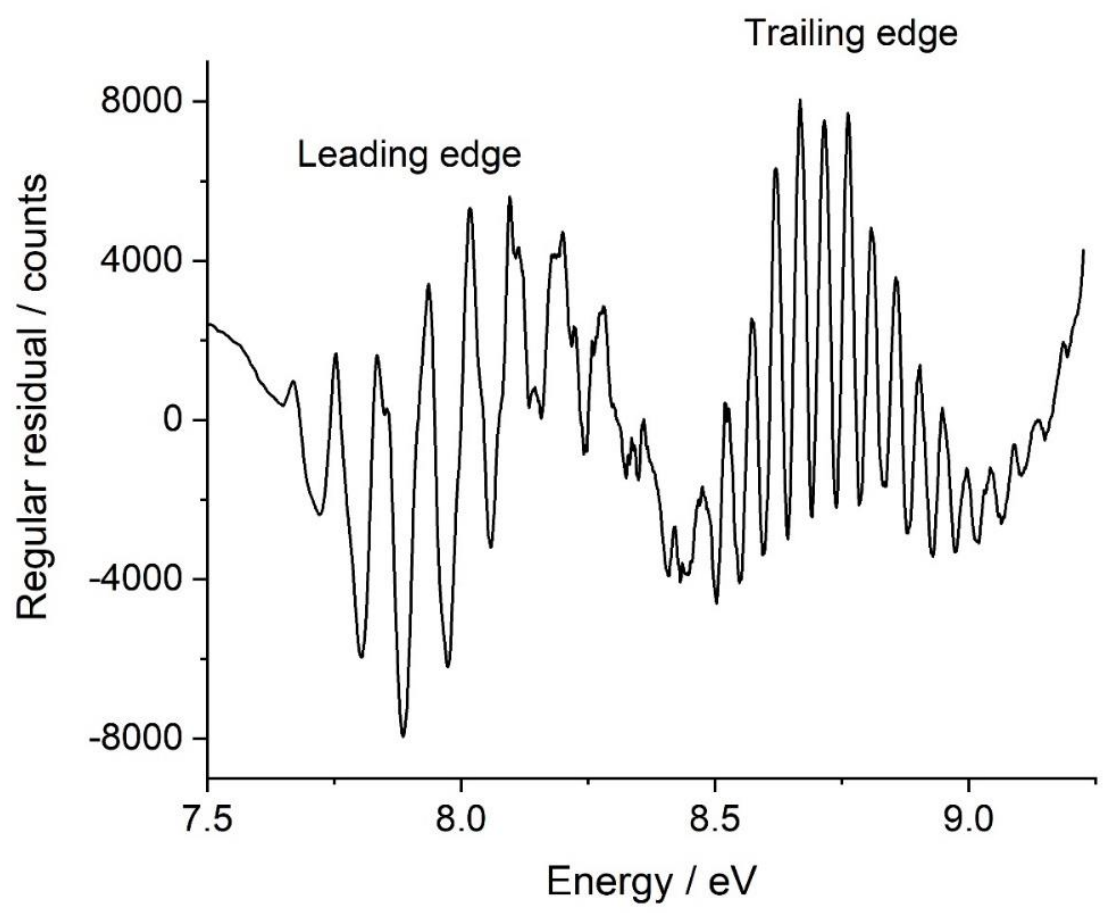


Table VIII. The a harmonic frequencies including their sequence numbers for the ground and ionic states for quadricyclane determined at the TZVP level. The full sequences are shown in the supplementary material as SM6. The modes labelled in ascending frequency are the same as the Franck-Condon profiles of active modes shown in Table IX.

\begin{tabular}{|c|c|c|c|c|}
\hline $\mathrm{X}^{1} \mathrm{~A}_{1}$ & ${ }^{2} \mathrm{~B}_{1}$ & ${ }^{2} \mathrm{~B}_{2}$ & ${ }^{2} \mathrm{~A}_{1}$ & ${ }^{2} \mathrm{~A}_{2}$ \\
\hline 6 & 2 & 5 & 7 & 6 \\
\hline 744 & 716 & 663 & 714 & 732 \\
\hline 8 & 7 & 8 & 9 & 9 \\
\hline 825 & 782 & 765 & 797 & 830 \\
\hline 12 & 8 & 12 & 12 & 15 \\
\hline 932 & 870 & 898 & 870 & 974 \\
\hline 15 & 13 & 13 & 15 & 17 \\
\hline 975 & 885 & 946 & 931 & 993 \\
\hline 17 & 17 & 18 & 17 & 18 \\
\hline 1022 & 1005 & 1066 & 1006 & 1035 \\
\hline 22 & 19 & 20 & 23 & 22 \\
\hline 1112 & 1055 & 1092 & 11511096 & 1190 \\
\hline 28 & 23 & 28 & 27 & 25 \\
\hline 1290 & 1220 & 1354 & 1284 & 1273 \\
\hline 29 & 26 & 29 & 28 & 29 \\
\hline 1381 & 1303 & 1397 & 1307 & 1379 \\
\hline 31 & 29 & 31 & 31 & 30 \\
\hline 1509 & 1409 & 1511 & 1484 & 1517 \\
\hline 32 & 29 & 32 & 32 & 31 \\
\hline 3085 & 2936 & 3127 & 3062 & 3110 \\
\hline 35 & 36 & 35 & 37 & 36 \\
\hline 3237 & 3256 & 3260 & 3273 & 3249 \\
\hline 39 & 39 & 39 & 39 & 38 \\
\hline 3270 & 3269 & 3290 & 3288 & 3258 \\
\hline
\end{tabular}

Table IX. Vibrationally excited states for the ${ }^{2} B_{2}$ state of quadricyclane using FranckCondon methods. Energy of the 0-0 transition: $60422 \mathrm{~cm}^{-1}$. The modes excited shown here are the $a_{1}$ frequencies for the ionic state shown, together with the number (n) of quanta excited as '^ $n$ '. binary and higher combination bands are separated by semicolons.

\begin{tabular}{|r|r|r|r|r|r|}
\hline $\begin{array}{r}\text { Energy } \\
\mathrm{cm}^{-1}\end{array}$ & $\begin{array}{r}\text { Modes excited } \\
+ \text { quanta }\end{array}$ & $\begin{array}{r}\text { Relative } \\
\text { intensity }\end{array}$ & $\begin{array}{r}\text { Energy } \\
\mathrm{cm}^{-1}\end{array}$ & $\begin{array}{r}\text { Modes excited } \\
+ \text { quanta }\end{array}$ & $\begin{array}{r}\text { Relative } \\
\text { intensity }\end{array}$ \\
\hline 0 & 0 & 897 & 2393 & $18^{\wedge} 1 ; 5^{\wedge} 2$ & 2526 \\
\hline 663 & $5^{\wedge} 1$ & 2513 & 2460 & $12^{\wedge} 2 ; 5^{\wedge} 1$ & 13640 \\
\hline 765 & $8^{\wedge} 1$ & 287 & 2494 & $18^{\wedge} 1 ; 8^{\wedge} 1 ; 5^{\wedge} 1$ & 340 \\
\hline 898 & $12^{\wedge} 1$ & 2604 & 2561 & $12^{\wedge} 2 ; 8^{\wedge} 1$ & 1350 \\
\hline 1066 & $18^{\wedge} 1$ & 276 & 2627 & $18^{\wedge} 1 ; 12^{\wedge} 1 ; 5^{\wedge} 1$ & 3461 \\
\hline 1327 & $5^{\wedge} 2$ & 5187 & 2654 & $5 \wedge$ & 6118 \\
\hline 1354 & $28^{\wedge} 1$ & 243 & 2681 & $28^{\wedge} 1 ; 5^{\wedge} 2$ & 1884 \\
\hline 1428 & $8^{\wedge} 1 ; 5^{\wedge} 1$ & 1285 & 2695 & $12^{\wedge} 3$ & 2598 \\
\hline 1562 & $12^{\wedge} 1 ; 5^{\wedge} 1$ & 10640 & 2724 & $29^{\wedge} 1 ; 5^{\wedge} 2$ & 549 \\
\hline 1663 & $12^{\wedge} 1 ; 8^{\wedge} 1$ & 690 & 2729 & $18^{\wedge} 1 ; 12^{\wedge} 1 ; 8^{\wedge} 1$ & 280 \\
\hline
\end{tabular}




\begin{tabular}{|r|r|r|r|r|r|}
\hline 1729 & $18^{\wedge} 1 ; 5^{\wedge} 1$ & 1214 & 2755 & $8^{\wedge} 1 ; 5^{\wedge} 3$ & 3634 \\
\hline 1797 & $12^{\wedge} 2$ & 3374 & 2779 & $5^{\wedge} 3 ; 1^{\wedge} 2$ & 306 \\
\hline 1964 & $18^{\wedge} 1 ; 12^{\wedge} 1$ & 795 & 2782 & $28^{\wedge} 1 ; 8^{\wedge} 1 ; 5^{\wedge} 1$ & 322 \\
\hline 1990 & $5^{\wedge} 3$ & 6721 & 2795 & $18^{\wedge} 2 ; 5^{\wedge} 1$ & 229 \\
\hline 2017 & $28^{\wedge} 1 ; 5^{\wedge} 1$ & 985 & 2856 & $8^{\wedge} 2 ; 5^{\wedge} 2$ & 487 \\
\hline 2061 & $29^{\wedge} 1 ; 5^{\wedge} 1$ & 273 & 2862 & $18^{\wedge} 1 ; 12^{\wedge} 2$ & 1023 \\
\hline 2092 & $8^{\wedge} 1 ; 5^{\wedge} 2$ & 2725 & 2889 & $12^{\wedge} 1 ; 5^{\wedge} 3$ & 24790 \\
\hline 2116 & $5^{\wedge} 2 ; 1^{\wedge} 2$ & 241 & 2916 & $28^{\wedge} 1 ; 12^{\wedge} 1 ; 5^{\wedge} 1$ & 2594 \\
\hline 2193 & $8^{\wedge} 2 ; 5^{\wedge} 1$ & 221 & 2959 & $29^{\wedge} 1 ; 12^{\wedge} 1 ; 5^{\wedge} 1$ & 670 \\
\hline 2225 & $12^{\wedge} 1 ; 5^{\wedge} 2$ & 20520 & 2990 & $12^{\wedge} 1 ; 8^{\wedge} 1 ; 5^{\wedge} 2$ & 6434 \\
\hline 2252 & $28^{\wedge} 1 ; 12^{\wedge} 1$ & 647 & 3014 & $12^{\wedge} 1 ; 5^{\wedge} 2 ; 1^{\wedge} 2$ & 580 \\
\hline 2296 & $29^{\wedge} 1 ; 12^{\wedge} 1$ & 159 & 2393 & $18^{\wedge} 1 ; 5^{\wedge} 2$ & 2526 \\
\hline 2326 & $12^{\wedge} 1 ; 8^{\wedge} 1 ; 5^{\wedge} 1$ & 3065 & 2460 & $12^{\wedge} 2 ; 5^{\wedge} 1$ & 13640 \\
\hline 2351 & $12^{\wedge} 1 ; 5^{\wedge} 1 ; 1^{\wedge} 2$ & 291 & 2494 & $18^{\wedge} 1 ; 8^{\wedge} 1 ; 5^{\wedge} 1$ & 340 \\
\hline
\end{tabular}

Figure 11. The quadricyclane $\mathrm{IE}_{1}{ }^{2} \mathrm{~B}_{2}$ state PES with calculated Franck-Condon cold band structure superimposed.

Wavenumber $/ \mathrm{cm}^{-1}$

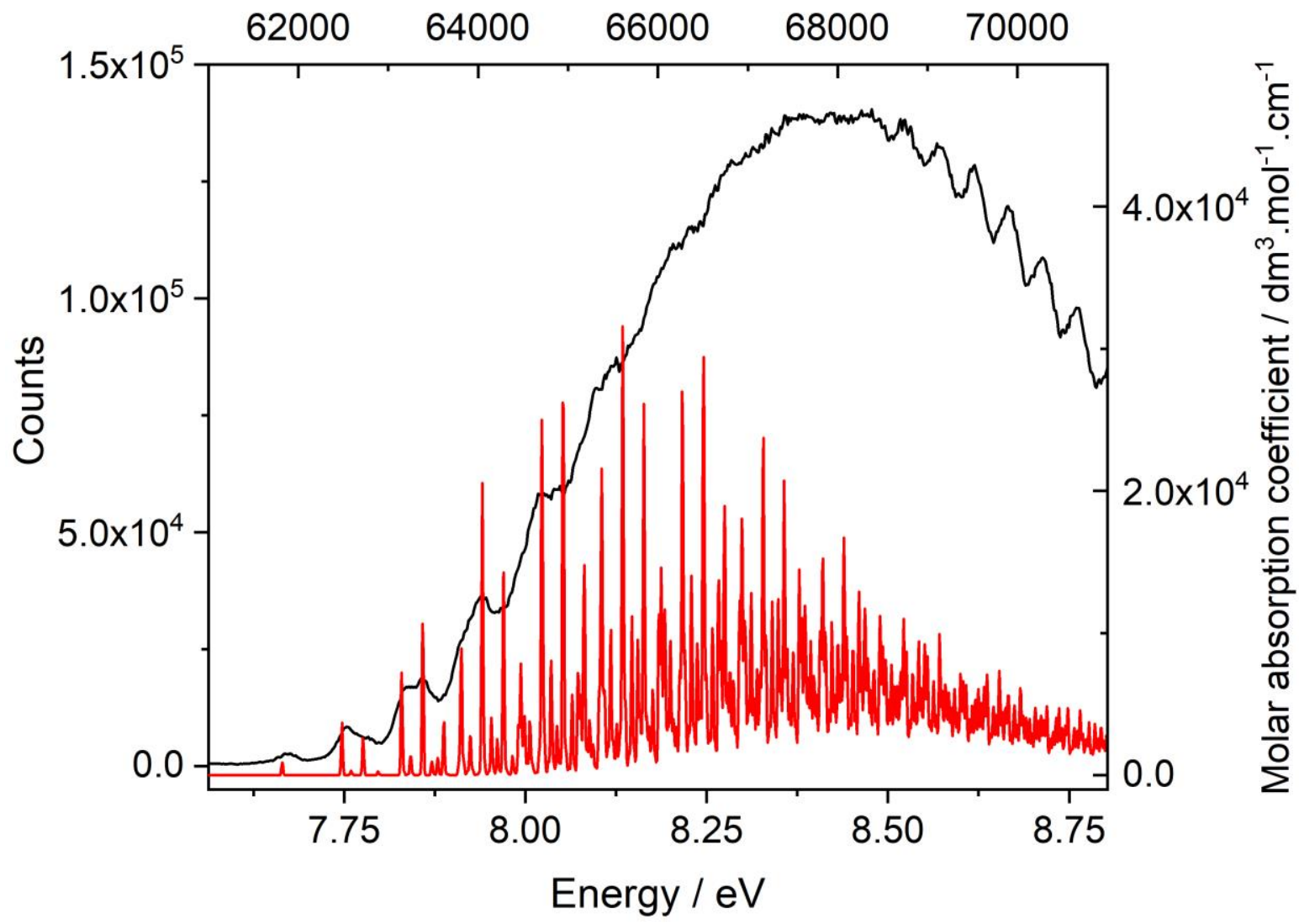

The next two ionzations for QC are the strongly overlapping doublet, centred on $10 \mathrm{eV}$, which we attribute to ${ }^{2} \mathrm{~A}_{2} \leq{ }^{2} \mathrm{~B}_{1}$. We have performed a fit of the observed PES, using two separate Gaussian functions, as shown in the supplementary material under SM3(c). The difference between the fitted functions and the PES is very small, and largely confined to the onset and 
trailing edges. This is where spectral interactions with adjacent peaks become relevant, and also where the anharmonicity of the PES states is neglected in the fit. The two ionizations are separated, experimentally for VIE and theoretically for $0^{0}$ bands, by $2726 \mathrm{~cm}^{-1}$ and $2904 \mathrm{~cm}^{-1}$ respectively. The Gaussian simulation widens the VIE to $9.73 \pm 0.05$ and $10.25 \pm 0.05 \mathrm{eV}$, a separation of $4194 \mathrm{~cm}^{-1}$. A summary of the lowest calculated vibrational states, given in Table $\mathrm{X}$, is superimposed on the two simulations. Those shown in red, have half-widths at halfmaximum (bandwidths) of $10 \mathrm{~cm}^{-1}$. In both spectra, there are no vibrational spectral features visible. The Tables show that several vibrational states are present in this small interval, making recognition of features in the spectrum impossible at this resolution. We have noted previously, ${ }^{87}$ that when two or more PES ionizations overlap, the effect is to degrade the spectral resolution of the higher energy one(s), owing to interference between the vibrational wave-trains of the lower IE on the higher IE. In short, the two ionic states are strongly coupled, and conical intersections lie between their minima, an observation first made by Baldea et al ${ }^{88,89}$ in a study of the PhF ionic states. Without directly including the inter-state vibronic coupling in our previous simulations, we found that the smaller the separation of two ionic states, the larger the bandwidth of the fitting functions to the vibrational states necessary to achieve a match to experiment. ${ }^{87}$ The bandwidth used in Figure 12, has been widened to HWHM of 400 $\mathrm{cm}^{-1}$ in blue, to match the nearly featureless IE.

Table $X$. The low-lying vibrationally excited states of the ${ }^{2} A_{2}$ and ${ }^{2} B_{1}$ ionic states for quadricyclane. The modes excited shown here are the $\mathbf{a}_{1}$ frequencies for the ionic state shown, together with the number (n) of quanta excited as '^n'. binary and higher combination bands are separated by semi-colons.

\begin{tabular}{|r|r|r|r|r|r|}
\hline \multicolumn{2}{|c|}{${ }^{2} \mathrm{~A}_{2}$ Energy 0-0 transition: $75188 \mathrm{~cm}^{-1}$} & \multicolumn{3}{|c|}{${ }^{2} \mathrm{~B}_{1}$ Energy 0-0 transition: $78092 \mathrm{~cm}^{-1}$} \\
\hline $\begin{array}{r}\text { Energy } \\
\mathrm{cm}^{-1}\end{array}$ & $\begin{array}{r}\text { Modes excited } \\
\text { +quanta }\end{array}$ & $\begin{array}{r}\text { Relative } \\
\text { intensity }\end{array}$ & $\begin{array}{r}\text { Energy } \\
\mathrm{cm}^{-1}\end{array}$ & $\begin{array}{r}\text { Modes excited } \\
+ \text { quanta }\end{array}$ & $\begin{array}{r}\text { Relative } \\
\text { intensity }\end{array}$ \\
\hline 0 & 0 & 14110 & 0 & 0 & 99620 \\
\hline 486 & $1^{\wedge} 2$ & 1032 & 657 & $1^{\wedge} 2$ & 1054 \\
\hline 556 & $2^{\wedge} 2$ & 225 & 716 & $5^{\wedge} 1$ & 13670 \\
\hline 732 & $5^{\wedge} 1$ & 25510 & 736 & $2^{\wedge} 1 ; 1^{\wedge} 1$ & 610 \\
\hline 830 & $8^{\wedge} 1$ & 1092 & 782 & $8^{\wedge} 1$ & 808 \\
\hline
\end{tabular}




\begin{tabular}{|r|r|r|r|r|r|}
\hline 974 & $14^{\wedge} 1$ & 1937 & 815 & $2^{\wedge} 2$ & 5577 \\
\hline 993 & $16^{\wedge} 1$ & 14220 & 870 & $11^{\wedge} 1$ & 95800 \\
\hline 1190 & $21^{\wedge} 1$ & 13070 & 885 & $13^{\wedge} 1$ & 27880 \\
\hline 1217 & $5^{\wedge} 1 ; 1^{\wedge} 2$ & 2528 & 947 & $3^{\wedge} 2$ & 283 \\
\hline 1273 & $24^{\wedge} 1$ & 1820 & 1005 & $17^{\wedge} 1$ & 4522 \\
\hline 1288 & $5^{\wedge} 1 ; 2^{\wedge} 2$ & 512 & 1055 & $19^{\wedge} 1$ & 33310 \\
\hline 1463 & $5^{\wedge} 2$ & 18700 & 1078 & $7^{\wedge} 1 ; 1^{\wedge} 1$ & 732 \\
\hline 1478 & $16^{\wedge} 1 ; 1^{\wedge} 2$ & 977 & 1220 & $23^{\wedge} 1$ & 16060 \\
\hline 1549 & $16^{\wedge} 1 ; 2^{\wedge} 2$ & 215 & 1303 & $26^{\wedge} 1$ & 17950 \\
\hline
\end{tabular}

Figure 12. The combined quadricyclane ${ }^{2} A_{2}(A)$ and ${ }^{2} B_{1}(B)$ states, separated by two Gaussian fits. These two bands strongly overlap in the observed PES, and their separation is discussed in the text. The cold band structure calculated by Franck-Condon methods is shown in red; the individual lines which have Half-Widths at Half-Maximum of $10 \mathrm{~cm}^{-1}$ have been widened to $\mathrm{HWHM}$ of $400 \mathrm{~cm}^{-1}$ in blue.
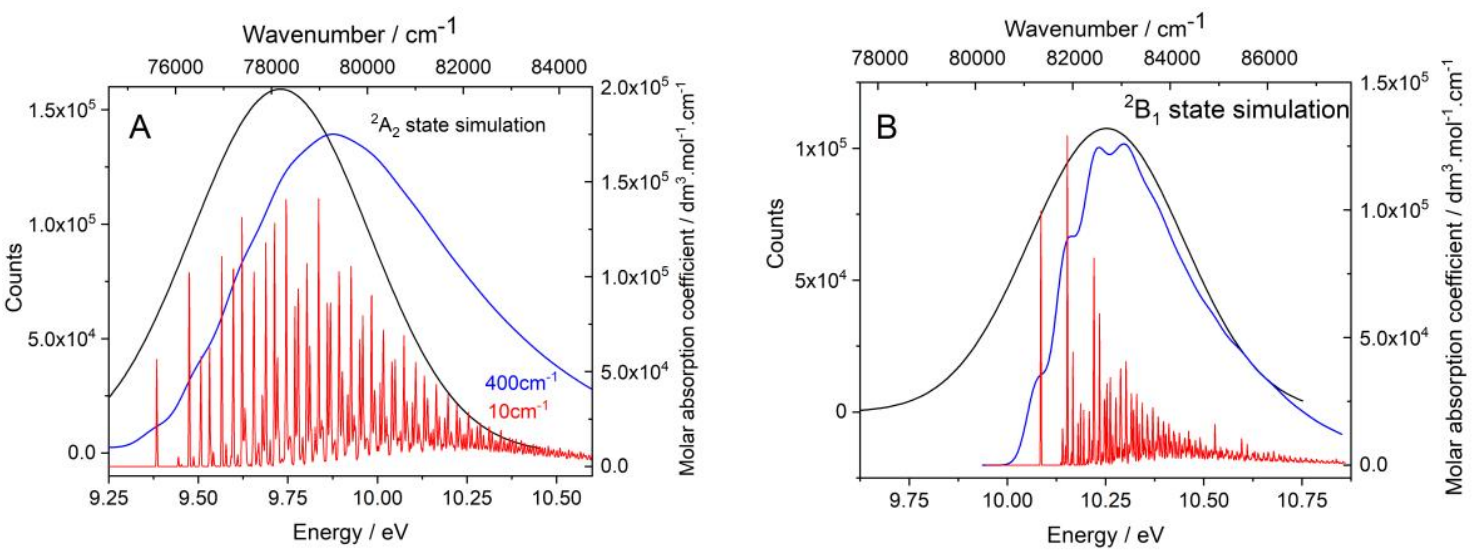

\section{CONCLUSIONS}

Our synthesis of QC showed that the previously accepted ${ }^{1} \mathrm{H}$ NMR coupling constants ${ }^{27-31}$ could not interpret the $300 \mathrm{MHz}$ spectrum; revised values were obtained by GIAO methods which show backwards compatibility with both 60 and $100 \mathrm{MHz}$ spectra. The QC spectrum at $300 \mathrm{MHz}$ shows $2^{\text {nd }}$ order effects are still present for both NBD and QC, but especially for QC.

We have determined theoretically the spin-spin coupling constants for QC in which all ${ }^{1} \mathrm{H}$ nuclei are coupled, and the spin coupling constants for symmetry related atoms are determined. These expose the weakness of simple ( $1^{\text {st }}$ order) analyses, where only coupling between chemically distinct atoms is considered and evaluated; this leads to the observed $1^{\text {st }}$ order coupling constants being sums of constants rather than individual values. ${ }^{31}$ 
Our synchrotron-based photoelectron spectra of NBD and QC show vibrational structure on the lowest IE in each case. NBD shows a vibrational progression of 18 members where the vibration frequency $(v)$ declines from 390 to $340 \mathrm{~cm}^{-1}$ with energy increase. Similarly, the lowest PES band for QC shows a vibrational progression of at least 9 members, but with $v$ decreasing from 703 to $660 \mathrm{~cm}^{-1}$.

The lowest AIEs of each symmetry were determined by MP4(SDQ) methods for each molecule. The adiabatic IE for NBD is assigned to the ${ }^{2} \mathrm{~B}_{1}$ state with a symmetry calculated frequency $\left(381 \mathrm{~cm}^{-1}\right)$. In contrast for $\mathrm{QC}$ it is assigned to the ${ }^{2} \mathrm{~B}_{2}$ state; here the a symmetry vibration frequency is calculated at $663 \mathrm{~cm}^{-1}$. The AIE sequences are NBD: ${ }^{2} \mathrm{~B}_{1}<{ }^{2} \mathrm{~A}_{1}<{ }^{2} \mathrm{~A}_{2}<$ ${ }^{2} \mathrm{~B}_{2}$ and QC: ${ }^{2} \mathrm{~B}_{2}<{ }^{2} \mathrm{~A}_{2}<{ }^{2} \mathrm{~B}_{1}<{ }^{2} \mathrm{~A}_{1}$. The symmetry sequences of ionic states are the same for MP2 and MP4 methods for the respective molecules.

For both NBD and QC, the overall PES vertical ionization energy (VIE) profiles from onset to $20 \mathrm{eV}$ for both compounds were closely reproduced by Tamm-Dancoff approximation (TDA) both in energies and intensities.

The vibrational structure within the lowest AIE for each of NBD and QC, determined by Franck-Condon methods, gave a good account of the observed spectra. However, the observed multiplets for $\mathrm{IE}_{1}$ in both cases, show that the envelope consists of a complex set of vibrations, rather than as single progressions. We have presented theoretical PES envelopes which include vibrational states for some higher ionizations, but the prospects for detecting these experimentally, will require a different technique than conventional PES, since there is substantial overlap between states of different symmetry, especially for QC. We have fitted two Gaussian functions to the combined ${ }^{2} \mathrm{~A}_{2}+{ }^{2} \mathrm{~B}_{1}$ states observed as a strongly overlapping doublet. The separated fucntions, after allowance for the lack of anharmonicity, and the effects of nearby ionizations on the leading and trailing edges, give a reasonable interpretation of the band. We are unable to perfrom the Franck-Condon analysis on the separate ${ }^{2} \mathrm{~A}_{1}$ state PES 
band, since the software available to us is limited to a single negative vibration frequency. At both the MP2, MP4 and MP4(SDQ) levels, the ${ }^{2} \mathrm{~A}_{1}$ state generates three such values.

\section{SUPPLEMENTARY MATERIAL}

See the supplementary material for additional information on each of the following: 1 . Synthesis of quadricyclane. 2. The GAIO calculated ${ }^{1} \mathrm{H}$ and ${ }^{13} \mathrm{C}$ magnetic shielding and spinspin coupling constants. 3. Fits to the lowest two ionization energies for norbornadiene and quadricyclane and the combined $3^{\text {rd }}$ state of QC. 4. The ground state equilibrium structures of NBD and QC. 5. Vibration frequencies of the ground and ionic states. 6. Comparison of the molecular structures of NBD and QC with experimental microwave and other spectral data. 7. Bond and ring critical points.

\section{ACKNOWLEDGEMENTS}

We thank: (a) the Elettra Synchrotron facility for a Grant of beamtime and C. Puglia (Uppsala University Sweden) and the Carl Tygger Foundation for making available the VGScienta SES-200 photoelectron analyser. (b) the Italian MIUR (under the project PON01010788); (c) the University of Edinburgh (Eddie3) and Edinburgh Parallel Computing Centre (Cirrus) super-computing facilities for support; (d) Prof. Malgorzata Biczysko for helpful discussions. Both experimental and simulated NMR spectra were processed using i-NMR Reader (version 6.1.7).${ }^{90}$ Numerical fitting was performed using Gnuplot-5.0.5; ${ }^{91}$ plotting used Origin 7.0, ${ }^{92}$ GaussView $^{93}$ and Avogadro. ${ }^{94}$

\section{AVAILABILITY OF DATA IN ARTICLE OR SUPPLEMENTARY MATERIAL.}

The data that support the findings of this study, including its supplementary material, will be available from the corresponding author upon reasonable request.

\section{APPENDIX}

A comparison of the experimental rotational constants with the present study is shown in Appendix Tables APP.I and APP.II. Rotational constants (A, B, C), give a relative measure of 
the overall shape, via the moments of inertia. The $\operatorname{CCSD}(\mathrm{T})$ data shows very close RC values for both $\mathrm{NBD}^{68}$ and $\mathrm{QC},{ }^{71}$ which differ from the MW data by less than $1 \%$. The results from the MP4(SDQ) ground state calculations, differ from the experimental data by a further small amount. The ground state structures of both NBD and QC determined by CCSD(T) procedures were very similar to those from $4^{\text {th }}$ order Møller-Plesset perturbation theory, which included single double and quadruple excitations (MP4(SDQ)). Fortunately, both were very similar to those from $2^{\text {nd }}$ order MP2 theory. In the case of NBD there is a further close structural similarity with calculations which included triples (MP4(SDTQ)) but these calculations ${ }^{38}$ appear to be more demanding than the $\operatorname{CCSD}(\mathrm{T})$ method itself.

In all our methods, the rotational constants, centrifugal distortion constants and dipole moments, are very close to microwave values. We believe that this is not accidental, but demonstrates the quality of the studies; this leads to confidence in the ionic state study.

Table APP.I A comparison of the microwave substitution structure for norbornadiene, rotational constants $(A, B, C)$ with the $X^{1} A_{1}$ equilibrium structure and with the lowest ionic states of each symmetry for NBD, determined at the MP4(SDQ) level.

\begin{tabular}{|c|c|c|c|c|c|c|c|}
\hline \multicolumn{7}{|c|}{ Norbornadiene } \\
\hline & $\mathrm{X}^{1} \mathrm{~A}_{1}$ & $\mathrm{X}^{1} \mathrm{~A}_{1}$ & $\mathrm{X}^{1} \mathrm{~A}_{1}$ & ${ }^{2} \mathrm{~B}_{1}$ & ${ }^{2} \mathrm{~A}_{1}$ & ${ }^{2} \mathrm{~B}_{2}$ & ${ }^{2} \mathrm{~A}_{2}$ \\
\hline Method & $\mathrm{MW}^{65}$ & $\mathrm{CCSD}(\mathrm{T})$ & $\mathrm{MP4}(\mathrm{SDQ})$ & $\mathrm{MP} 4(\mathrm{SDQ})$ & $\mathrm{MP} 4(\mathrm{SDQ})$ & $\mathrm{MP4}$ (SDQ) & $\mathrm{MP4}$ (SDQ) \\
\hline Energy / eV & & & 0.0 & 8.185 & 9.183 & 10.607 & 10.998 \\
\hline Bond $\mathrm{C}_{1}-\mathrm{C}_{2} / \AA$ & - & 1.5387 & 1.5387 & 1.5202 & 1.5072 & 1.5284 & 1.6083 \\
\hline Bond $\mathrm{C}_{2}=\mathrm{C}_{3} / \AA$ & - & 1.3368 & 1.3367 & 1.3770 & 1.3633 & 1.3315 & 1.2999 \\
\hline Bond $\mathrm{C}_{1}-\mathrm{C}_{7} / \AA$ & - & 1.5520 & 1.5520 & 1.5443 & 1.6154 & 1.6527 & 1.5417 \\
\hline $\mathrm{A} / \mathrm{MHz}$ & $4273.628(1)$ & 4279.484 & 4315.7355 & 3988.6715 & 4410.9638 & 4233.4797 & 4137.4251 \\
\hline $\mathrm{B} / \mathrm{MHz}$ & $3610.300(1)$ & 3611.745 & 3617.8461 & 3849.1624 & 3654.6405 & 3406.5428 & 3493.2552 \\
\hline $\mathrm{C} / \mathrm{MHz}$ & $3186.437(1)$ & 3182.315 & 3184.0941 & 3473.6487 & 3024.1345 & 3190.4099 & 3186.4828 \\
\hline
\end{tabular}

Table APP.II. Structural details of $\mathrm{QC}$ in the ground $\mathrm{X}^{\mathbf{1}} \mathrm{A}_{\mathbf{1}}$ equilibrium structure and first ionic states of each symmetry, calculated rotational constants $(A, B, C)$, determined at the MP4(SDQ) level.

\begin{tabular}{|c|c|c|c|c|c|c|c|}
\hline \multicolumn{7}{|c|}{ Quadricyclane } \\
\hline & $\mathrm{X}^{1} \mathrm{~A}_{1}$ & $\mathrm{X}^{1} \mathrm{~A}_{1}$ & $\mathrm{X}^{1} \mathrm{~A}_{1}$ & ${ }^{2} \mathrm{~B}_{2}$ & ${ }^{2} \mathrm{~A}_{2}$ & ${ }^{2} \mathrm{~B}_{1}$ & ${ }^{2} \mathrm{~A}_{1}$ \\
\hline Method & $\mathrm{MW}^{67}$ & $\mathrm{CCSD}(\mathrm{T})$ & $\mathrm{MP} 4(\mathrm{SDQ})$ & $\mathrm{MP} 4(\mathrm{SDQ})$ & $\mathrm{MP} 4(\mathrm{SDQ})$ & $\mathrm{MP} 4(\mathrm{SDQ})$ & $\mathrm{MP} 4(\mathrm{SDQ})$ \\
\hline Energy /eV & & & 0.0 & 7.482 & 9.185 & 9.757 & 10.634 \\
\hline
\end{tabular}




\begin{tabular}{|c|c|c|c|c|c|c|c|}
\hline & & & & & & & \\
\hline Bond $\mathrm{C}_{1}-\mathrm{C}_{2} / \AA$ & - & 1.5217 & 1.5143 & 1.4977 & 1.5993 & 1.5421 & 1.4846 \\
\hline Bond $\mathrm{C}_{2}-\mathrm{C}_{6} / \AA$ & - & 1.5187 & 1.5458 & 1.4756 & 1.5059 & 1.6462 & 1.6015 \\
\hline Bond $\mathrm{C}_{1}-\mathrm{C}_{7} / \AA$ & - & 1.5149 & 1.5139 & 1.5356 & 1.5027 & 1.4836 & 1.5509 \\
\hline $\mathrm{A} / \mathrm{MHz}$ & $4408.2184(2)$ & 4406.271 & 4426.9300 & 4384.8284 & 4492.9622 & 4381.1570 & 4575.2727 \\
\hline $\mathrm{B} / \mathrm{MHz}$ & $4345.5142(2)$ & 4347.729 & 4368.0907 & 4260.3649 & 4216.3741 & 4321.8614 & 4059.4725 \\
\hline $\mathrm{C} / \mathrm{MHz}$ & $3256.2893(2)$ & 3256.391 & 3267.6349 & 3427.2813 & 3161.8450 & 3123.9866 & 3266.8885 \\
\hline
\end{tabular}

\section{REFERENCES}

1. M. H. Palmer, M. Coreno, M. de Simone, C. Grazioli, S. Vrønning Hoffmann, and N. C. Jones, J. Chem. Phys. 150, 194305 (2019). https://doi.org/10.1063/1.5096254

2. M. H. Palmer, R. A. Aitken, M. Coreno, M. de Simone, C. Grazioli, S. Vrønning Hoffmann, and N. C. Jones, J. Chem. Phys. 152, 144301 (2020). https://doi.org/10.1063/1.5142268

3. M. H. Palmer, S. Vrønning Hoffmann, N. C. Jones, M. Coreno, M. de Simone, and C. Grazioli, J. Chem. Phys. 151, 084304 (2019). https://doi.org/10.1063/1.5115997

4. M. H. Palmer, S. Vrønning Hoffmann, N. C. Jones, M. Coreno, M. de Simone, C. Grazioli, and R. A. Aitken, J. Chem. Phys. 153, 054301 (2020). https://doi.org/10.1063/50011088

5. U. Bauer, L. Fromm, C. Weiß, P. Bachmann, F. Späth, F. Düll, J. Steinhauer, W. Hieringer, A. Görling, A. Hirsch, H.-P. Steinrück, and C. Papp, J. Phys. Chem. C 123, 7654-7664 (2019). https://doi.org/10.1021/acs.jpcc.8b03746

6. U. Bauer, L. Fromm, C. Weiß, F. Späth, P. Bachmann, F. Düll, J. Steinhauer, S. Matysik, A. Pominov, A. Görling, A. Hirsch, H.-P. Steinrück, and C. Papp, J. Chem. Phys. 150, 184706 (2019). https://doi.org/10.1063/1.5095583

7. O. Brummel, F. Waidhas, U. Bauer, Y. Wu, S. Bochmann, H-P. Steinrück, C. Papp, J. Bachmann, and J. Libuda, J. Phys. Chem. Lett. 8, 2819-2825 (2017). https://doi.org/10.1021/acs.jpclett.7b00995

8. C. Philippopoulos, D. Economou, C. Economou, and J. Marangozis, Ind. Eng. Chem. Prod. Res. Dev. 22, 627-633 (1983). https://doi.org/10.1021/i300012a021

9. B. E. Tebikachew, H. B. Li, A. Pirrotta, K. Borjesson, G. C. Solomon, J. Hihath, and K.

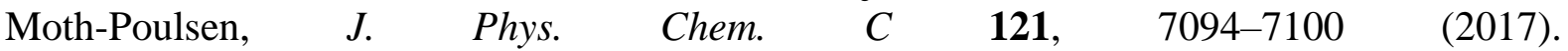
https://doi.org/10.1021/acs.jpcc.7b00319

10. B. E. Tebikachew, F.Edhborg, N. Kann, B. Albinsson, and K. Moth-Poulsen, Phys. Chem. Chem. Phys. 20, 23195-23201 (2018). https://doi.org/10.1039/C8CP04329A

11. M. Quant, A. Lennartson, A. Dreos, M. Kuisma, P. Erhart, K. Börjesson, and K. MothPoulsen, Chem. Eur. J. 22, 13265-13274 (2016). https://doi.org/10.1002/chem.201602530

12. A. Cuppoletti, J. P. Dinnocenzo, J. L. Goodman, and I. R. Gould, J. Phys. Chem. A 103, 11253-11256 (1999). https://doi.org/10.1021/jp992884i

13. M. Bertram, F. Waidhas, M. Jevric, L. Fromm, C. Schuschke, M. Kastenmeier, A. Görling, K. Moth-Poulsen, O. Brummel, and J. Libuda, J. Chem. Phys. 152, 044708 (2020). https://doi.org/10.1063/1.5137897

14. A. Dreos, Z. Wang, B. E. Tebikachew, K Moth-Poulsen, and J. Andreasson, J. Phys. Chem. Lett. 9, 6174-6178 (2018). https://doi.org/10.1021/acs.jpclett.8b02567

15. M. Quant, A. Hamrin, A. Lennartson, P. Erhart, and K. Moth-Poulsen, J. Phys. Chem. C 123, 7081-7087 (2019). https://doi.org/10.1021/acs.jpcc.9b02111

16. P. Bischof, J. A. Hashmall, E Heilbronner, and V. Hornung, Helv. Chim. Acta 52, 17451749 (1969). https://doi.org/10.1002/hlca.19690520631

17. D. A. Demeo and A. J. Yencha, J. Chem. Phys. 53, 4536-4543 (1970). https://doi.org/10.1063/1.1673985 
18. E. Heilbronner and H.-D. Martin, Helv. Chim. Acta 55, 1490-1502 (1972). https://doi.org/10.1002/hlca.19720550514

19. E. Lindholm, C. Fridh, and L. Asbrink, Faraday Discuss. Chem. Soc. 54, 127-138 (1972). https://doi.org/10.1039/DC9725400127

20. K. Ohno, T. Ishida, Y. Naitoh, and Y. Izumi, J. Am. Chem. Soc. 107, 8082-8086 (1985). https://doi.org/10.1021/ja00312a048

21. G. Bieri, F. Burger, E. Heilbronner, and J. P. Maier, Helv. Chim. Acta 60, 2213-2233 (1977). https://doi.org/10.1002/hlca19770600714

22. H. D. Roth and M. L. M. Schilling, J. Am. Chem. Soc. 103, 7210-7217 (1981). https://doi.org/10.1021/ja00414a028

23. K. Ishiguro, I. V. Khudyakov, P. F. McGarry, N. J. Turro, and H. D. Roth, J. Am. Chem. Soc. 116, 6933-6934 (1994). https://doi.org/10.1021/ja00094a057

24. R. D. Bach, I. L. Schilke, and H. B. Schlegel, J. Org. Chem. 61, 4845-4847 (1996). https://doi.org/10.1021/jo952268s

25. Y. Inadomi, K. Morihashi and O. Kikuchi, J. Molec. Struct. (THEOCHEM), 434, 59-66 (1998).

26. NIST Chemistry WebBook SRD 69;

https:webbook.nist.govcgicbook.cgi?ID=C121460\&Mask=20\#Ion-Energetics

https:webbook.nist.govcgicbook.cgi?ID=C278068\&Mask=69

27. R. Radeglia, H. Poleschner, and G. Haufe, Magn. Reson. Chem. 31, 639-641 (1993). https://doi.org/10.1002/mrc.1260310706

28. W. Offermann, Magn. Reson. Chem. 20, 203-204 (1982). https://doi.org/10.1002/mrc.1270200402

29. T. Parella, F. Sánchez-Ferrando, and A. Virgili, Magn. Reson. Chem. 33, 196-200 (1995). https://doi.org/10.1002/mrc.1260330308

30. R. Hübers, M. Klessinger, and K. Wilhelm, Magn. Reson. Chem. 24, 1016-1019 (1986). https://doi.org/10.1002/mrc.1260241118

31. P. Laszlo and P. von R. Schleyer, J. Am. Chem. Soc. 86, 1171-1179 (1964). https://doi.org/10.1021/ja01060a044

32. C. D. Smith, Org. Synth. 51, 133-135 (1971). https://doi.org/10.15227/orgsyn.051.0133

33. G. S. Hammond, N. J. Turro, and A. Fischer, J. Am. Chem. Soc. 83, 4674-4675 (1961). https://doi.org/10.1021/ja01483a051

34. W. G. Dauben and R. L. Cargill, Tetrahedron 15, 197-201 (1961). https://doi.org/10.1016/0040-4020(61)80026-4

35. L. Pan, R. Feng, H. Peng, X. E, J.-J. Zou, L. Wang, and X. Zhang, RSC Adv. 4, 5099851001 (2014). https://doi.org/10.1039/C4RA08868A

36. O. Baumgärtel and G. Szeimies, Chem. Ber. 116, 2180-2204 (1983). https://doi.org/10.1002/cber.19831160612

37. P. L. Beaulieu, A. Kabo, and D. G. Garratt, Can. J. Chem. 58, 1014-1020 (1980). https://doi.org/10.1139/v80-159

38. Gaussian 16 Revision A.03 M. J. Frisch G. W. Trucks H. B. Schlegel G. E. Scuseria M. A. Robb J. R. Cheeseman G. Scalmani V. Barone G. A. Petersson H. Nakatsuji X. Li M. Caricato A. V. Marenich J. Bloino B. G. Janesko R. Gomperts B. Mennucci H. P. Hratchian J. V. Ortiz A. F. Izmaylov J. L. Sonnenberg D. Williams-Young F. Ding F. Lipparini F. Egidi J. Goings B. Peng A. Petrone T. Henderson D. Ranasinghe V. G. Zakrzewski J. Gao N. Rega G. Zheng W. Liang M. Hada M. Ehara K. Toyota R. Fukuda J. Hasegawa M. Ishida T. Nakajima Y. Honda O. Kitao H. Nakai T. Vreven K. Throssell J. A. Montgomery Jr. J. E. Peralta F. Ogliaro M. J. Bearpark J. J. Heyd E. N. Brothers K. N. Kudin V. N. Staroverov T. A. Keith R. Kobayashi J. Normand K. Raghavachari A. P. Rendell J. C. Burant S. S. Iyengar J. Tomasi M. 
Cossi J. M. Millam M. Klene C. Adamo R. Cammi J. W. Ochterski R. L. Martin K. Morokuma O. Farkas J. B. Foresman and D. J. Fox Gaussian Inc. Wallingford CT 2016.

39. H.-J. Werner P. J. Knowles F. R. Manby M. Schütz P. Celani T. Korona R. Lindh A. Mitrushenkov G. Rauhut K. R. Shamasundar T. B. Adler R. D. Amos A. Bernhardsson A. Berning D. L. Cooper M. J. O. Deegan A. J. Dobbyn F. Eckert E. Goll C. Hampel A. Hesselmann G. Hetzer T. Hrenar G. Jansen C. Köppl Y. Liu A. W. Lloyd R. A. Mata A. J. May S. J. McNicholas W. Meyer M. E. Mura A. Nicklaß D. P. O'Neill P. Palmieri K. Pflüger R. Pitzer M. Reiher T. Shiozaki H. Stoll A. J. Stone R. Tarroni T. Thorsteinsson M. Wang and A. Wolf MOLPRO Version 2012.1 a package of ab initio programs 2012 see http:www.molpro.net.

40. H.-J. Werner and P. J. Knowles, J. Chem. Phys. 82, 5053-5063 (1985). https://doi.org/10.1063/1.448627

41. M. J. Frisch, M. Head-Gordon, and J. A. Pople, Chem. Phys. Lett. 166, 275-280 (1990). https://doi.org/10.1016/0009-2614(90)80029-D

42. M. J. Frisch, M. Head-Gordon, and J. A. Pople, Chem. Phys. Lett. 166, 281-289 (1990). https://doi.org/10.1016/0009-2614(90)80030-H

43. G. D. Purvis III and R. J. Bartlett, J. Chem. Phys. 76, (1982) 1910-1918. https://doi.org/10.1063/1.443164

44. S. J. Cole and R. J. Bartlett, J. Chem. Phys. 86, 873-881 (1987). https://doi.org/10.1063/1.452289

45. R. Krishnan and J. A. Pople, Int. J. Quantum Chem. 14, 91-100 (1978). https://doi.org/10.1002/qua.560140109

46. G. W. Trucks, J. D. Watts, E. A. Salter, and R. J. Bartlett, Chem. Phys. Lett. 153, 490-495 (1988). https://doi.org/10.1016/0009-2614(88)85248-5

47. G. W. Trucks, E. A. Salter, C. Sosa, and R. J. Bartlett, Chem. Phys. Lett. 147, 359-366 (1988). https://doi.org/10.1016/0009-2614(88)80249-5

48. J. Schirmer and L. S. Cederbaum, J. Phys. B: At. Mol. Phys. 11, 1889-1900 (1978). https://doi.org/10.1088/0022-37001111006

49. I. H. Hillier, M. A. Vincent, M. F. Guest, and W. von Niessen, Chem. Phys. Lett. 134, 403406 (1987). https://doi.org/10.1016/0009-2614(87)87162-2

50. M. F. Guest, I. J. Bush, H. J. J. Van Dam, P. Sherwood, J. M. H. Thomas, J. H. Van Lenthe, R. W. A. Havenith, and J. Kendrick, Mol. Phys. 103, 719-747 (2005). https://doi.org/10.1080/00268970512331340592

51. V. Barone, J. Bloino, M. Biczysko, and F. Santoro, J. Chem. Theory Comput. 5, 540-554 (2009). https://doi.org/10.1021/ct8004744

52. J. Bloino, M. Biczysko, F. Santoro, and V. Barone, J. Chem. Theory Comput. 6, 1256-1274 (2010). https://doi.org/10.1021/ct9006772

53. A. Baiardi, J. Bloino, and V. Barone, J. Chem. Theory Comput. 9, 4097-4115 (2013). https://doi.org/10.1021/ct400450k

54. J. R. Cheeseman, G. W. Trucks, T. A. Keith, and M. J. Frisch, J. Chem. Phys. 104, 54975509 (1996). https://doi.org/10.1063/1.471789

55. K. Wolinski, J. F. Hilton, and P. Pulay, J. Am. Chem. Soc. 112, 8251-8260 (1990). https://doi.org/10.1021/ja00179a005

56. R. Ahlrichs and P. R. Taylor, J. Chim. Phys. 78, 315-324 (1981). https://doi.org/10.1051/jcp1981780315

57. P. C. Hariharan and J. A. Pople, Theor. Chim. Acta 28 (1973) 213-222. https://doi.org/10.1007/BF00533485

58. F. Weigend, Phys. Chem. Chem. Phys. 8, 1057-1065 (2006). https://doi.org/10.1039/B515623H 
59. V. Barone, in Recent Advances in Density Functional Methods, Part I, Ed. D. P. Chong (World Scientific Publ. Co., Singapore, 1996). Chemistry 1, 287-334 (1995).

60. V. Barone and S. Fliszar, J. Molec. Struct. (THEOCHEM) 369, 29-37 (1996). https://doi.org/10.1016/S0166-1280(96)04581-2

61. A. Yokozeki and K. Kuchitsu, Bull. Chem. Soc. Jpn. 44, 2356-2363(1971). https://doi.org/10.1246/bcsj.44.2356

62. Y. Morino, K. Kuchitsu, and A. Yokozeki, Bull. Chem. Soc. Jpn. 40, 1552 (1967). https://doi.org/10.1246/bcsj.40.1552

63. L. Doms, H. J. Geise, C. Van Alsenoy, L. Van den Enden, and L. Schaefer, J. Mol. Struct. 129, 299-314 (1985). https://doi.org/10.1016/0022-2860(85)80173-3

64. J. W. Emsley J. C. Lindon, Mol. Phys. 29, 531-538 (1975). https://doi.org/10.1080/00268977500100441

65. K. C. Cole and D. F. R. Gilson, J. Mol. Struct. 82, 71-75 (1982). https://doi.org/10.1016/0022-2860(82)85235-6

66. W. A. Heeschen, D. W. Alderman, and D. M. Grant, J. Phys.Chem. 92, 6504-6511 (1988). https://doi.org/10.1021/j100334a008

67. G. Knuchel, G. Grassi, B. Vogelsanger, and A. Bauder, J. Am. Chem. Soc. 115, 1084510848 (1993). https://doi.org/10.1021/ja00076a047

68. B. Vogelsanger and A. Bauder, J. Mol. Spectrosc. 130, 249-257 (1988). https://doi.org/10.1016/0022-2852(88)90298-6

69. J. Demaison J. Vogt G. Wlodarczak 'Rotational and Related Constants of Diamagnetic Asymmetric Top Molecules'; 1. Introduction: Landolt-Börnstein - Group II Molecules and Radicals; Vol. 19B (Rotational and Related Constants of Diamagnetic Asymmetric Top Molecules). W. Hüttner (ed.) SpringerMaterials (1992);

http://materials.springer.comlbdocssm_lbs_978-3-540-69986-6_1; (Springer-Verlag Berlin Heidelberg 1992). https://doi.org/10.1007/10048563_1

70. B. Vogelsanger and A. Bauder, J. Mol. Spectrosc. 136, 62-67 (1989). https://doi.org/10.1016/0022-2852(89)90219-1

71. C. Aroulanda, P. Lesot, D. Merlet, and J. Courtieu, J. Phys. Chem. A 107, 10911-10918 (2003). https://doi.org/10.1021/jp030137m

72. D. W. Rogers and F. J. McLafferty, J. Phys. Chem. A 103, 8733-8737 (1999). https://doi.org/10.1021/jp992093g

73. K. Raghavachari, R. C. Haddon, and H. D. Roth, J. Am. Chem. Soc. 105, 3110-3114 (1983). https://doi.org/10.1021/ja00348a026

74. I. W. Levin and W. C. Harris, Spectrochim. Acta 29A, 1815-1834 (1973). https://doi.org/10.1016/0584-8539(73)80167-9 Interpretation of the vibrational spectra of bicyclic hydrocarbons: norbornane and norbornadiene

75. R. T. Boeré, J. A. Eng, K. Preuss, M. Parvez, C. D. Bryan, and A. W. Cordes, Can. J. Chem. 72, 1171-1180. https://doi.org/10.1139/v94-150

76. L. B. Krivdin, Magn. Reson. Chem. 42, 919-930 (2004).

77. T. Enevoldsen, J. Oddershede, and S.P.A. Sauer, Theoret. Chem. Acc. 100, 275-284 (1998). https://doi.org/10.1007/s002140050388

78. R. Hoffmann, A. Imamura, and W. J. Hehre, J. Am. Chem. Soc. 90, 1499-1509 (1968). https://doi.org/10.1021/ja01008a018

79. R. Hoffmann, E. Heilbronner, and R. Gleiter, J. Am. Chem. Soc. 92, 706-707 (1970). https://doi.org/10.1021/ja00706a051

80. R. Hoffmann, Acc. Chem. Res. 4, 1-9 (1971). https://doi.org/10.1021/ar50037a001

81. T. Kobayashi, Phys. Lett. 69A, 31-33 (1978). https://doi.org/10.1016/03759601(78)90427-9 
82. M. H. Kibel, M. K. Livett, and G. L. Nyberg, J. Electron Spectrosc. Rel. Phenom. 15, 275280 (1979). https://doi.org/10.1016/0368-2048(79)87044-9

83. W. Von Niessen and G. H. F. Diercksen, J. Electron Spectrosc. Rel. Phenom. 16, 351-357 (1979). https://doi.org/10.1016/0368-2048(79)80031-6

84. M. H. Palmer, J. Molec. Struct. 161, 333-345 (1987). https://doi.org/10.1016/00222860(87)85085-8

85. H.-D. Martin, C. Heller, E. Haselbach, and Z. Lanyjova, Helv. Chim. Acta 57, 465-472 (1974). https://doi.org/10.1002/hlca.19740570220

86. E. Haselbach and H.-D. Martin, Helv. Chim. Acta 57, 472-480 (1974). https://doi.org/10.1002/hlca.19740570221

87. M.H. Palmer, T. Ridley, S. Vrønning Hoffmann, N. C. Jones, M. Coreno, M. de Simone, C. Grazioli, M. Biczysko, and A. Baiardi, J. Chem. Phys. 142, 134301 (2015); https://doi.org/10.1063/1.4916120

88. Baldea, J. Franz, P. G. Szalay and H. Koppel, Chem. Phys., 338, 207 (2007)

89. E. Gindensperger, I. Baldea, P. G. Szalay and H. Koppel, Chem. Phys., 338, 207 (2007).

90. i-NMR Reader (version 6.1.7).www.inmr.net

91. Gnuplot Release 5.0.7; http:www.gnuplot.info

92. Origin Version 2019 OriginLab Corporation Northampton MA USA.

93. Gauss View Version 6.1 R. Dennington T.A. Keith and J.M. Millam Semichem Inc. Shawnee Mission KS 2016.

94. Avogadro: an open-source molecular builder and visualization tool. Version 1.XX. http:avogadro.cc 


\section{Figure2 Palmer et al}

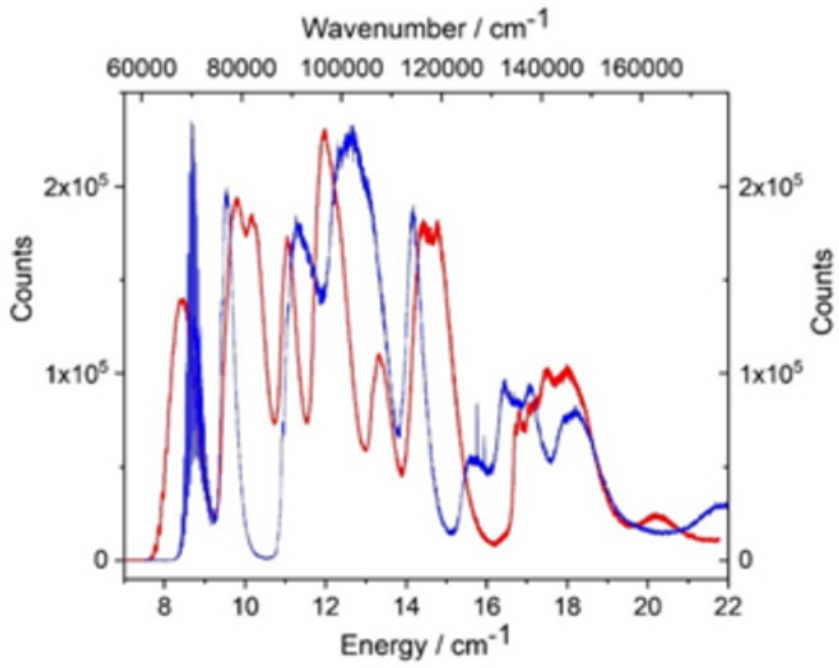


Figure 3. Palmer et al

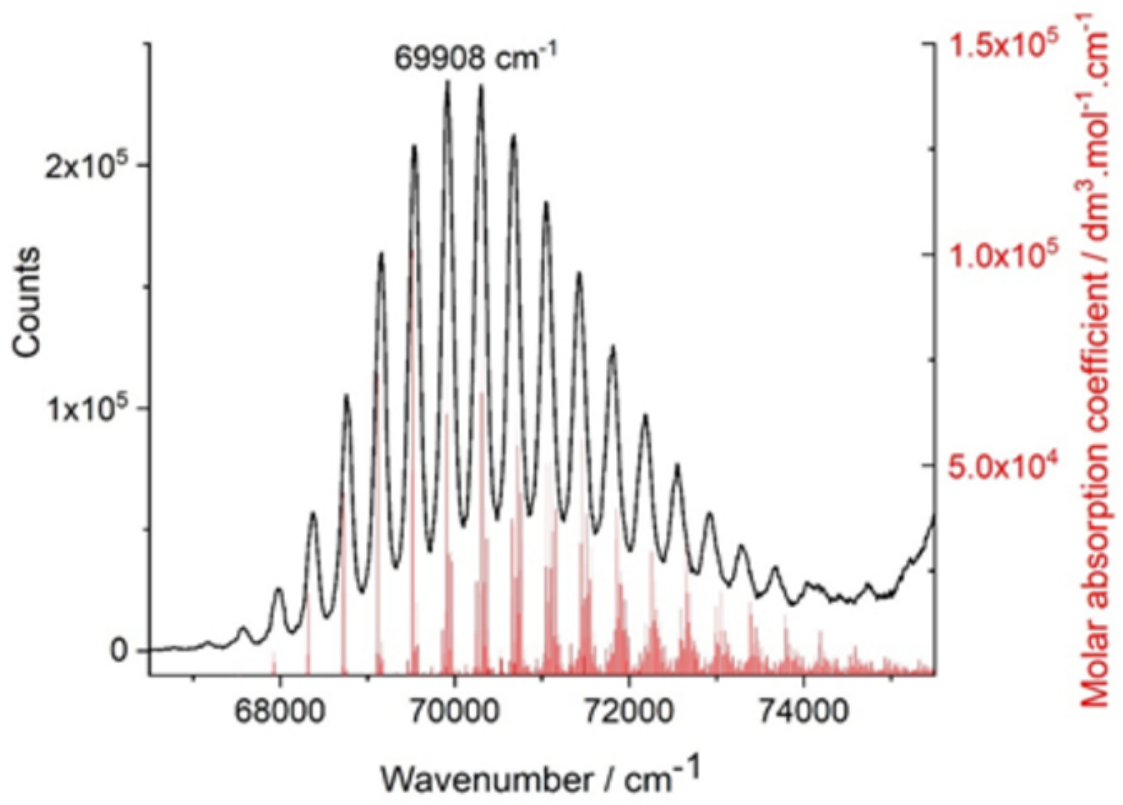




\section{Figure4 Palmer et al}
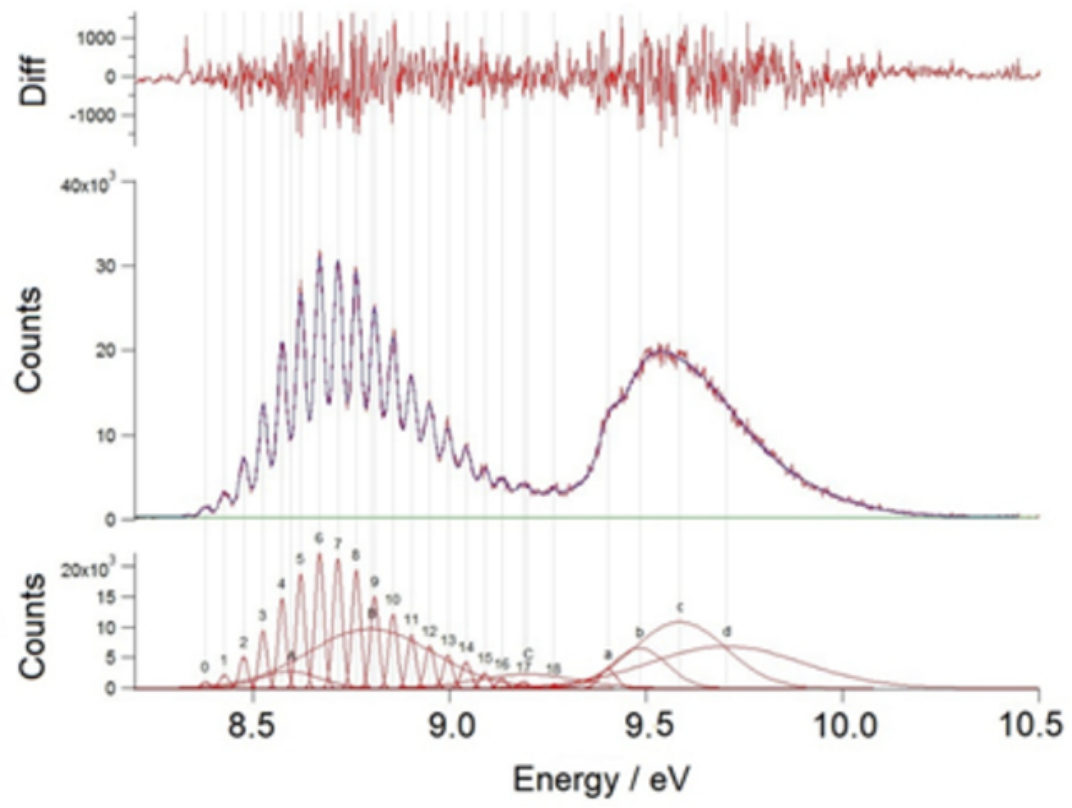


\section{Figure5 Palmer et al}

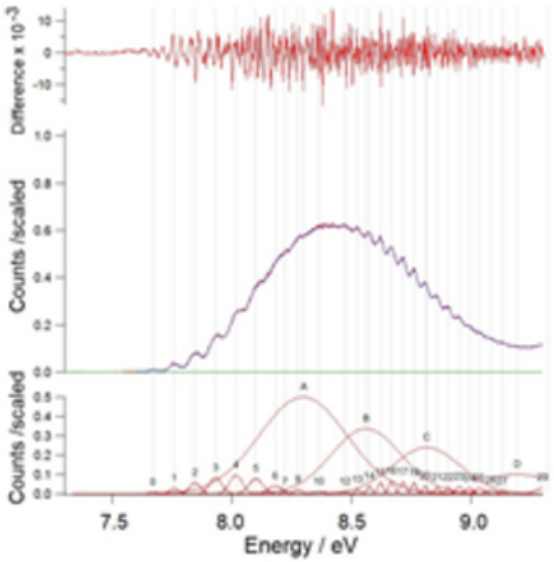


Figure6 Palmer et al

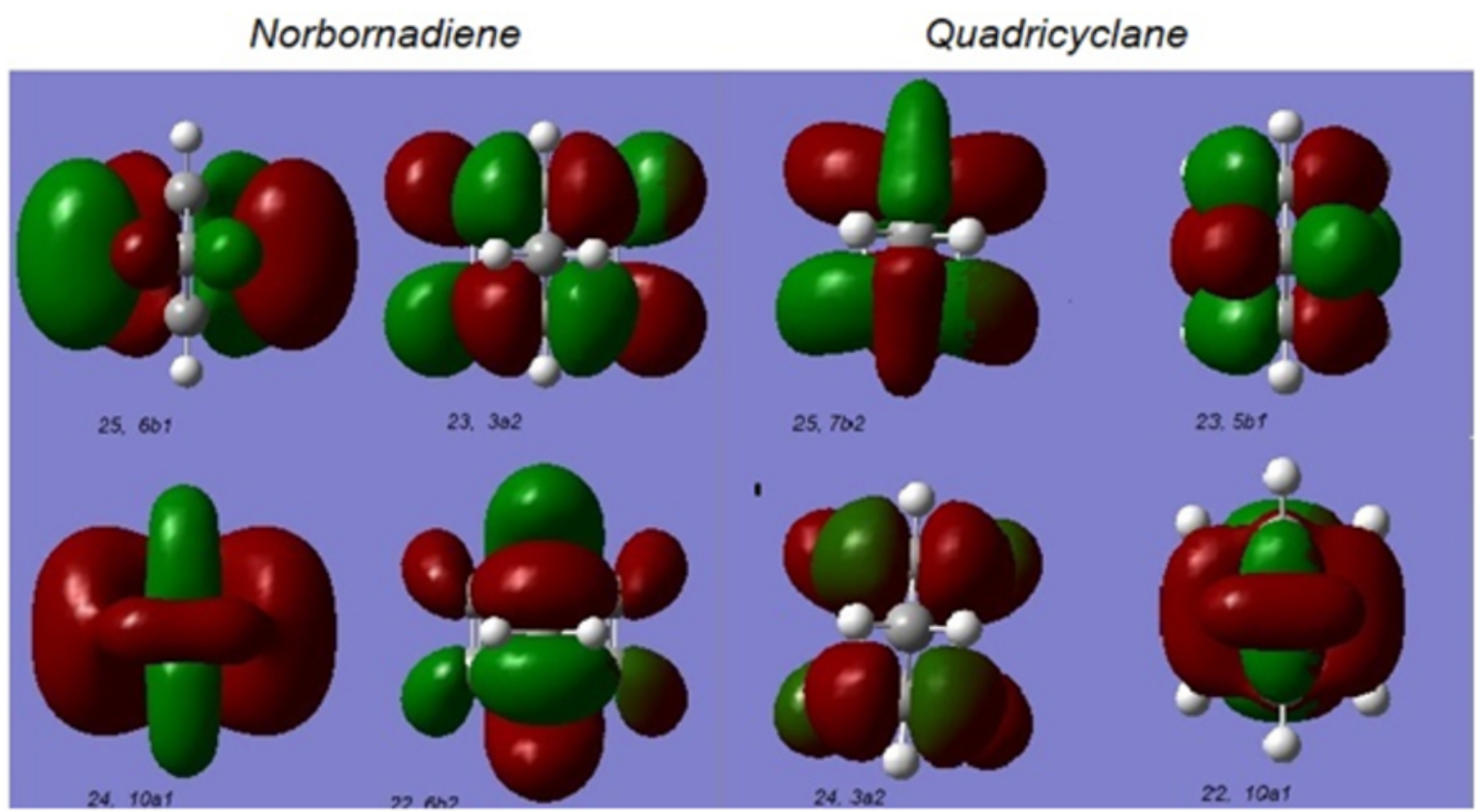


Figure8 Palmer et al

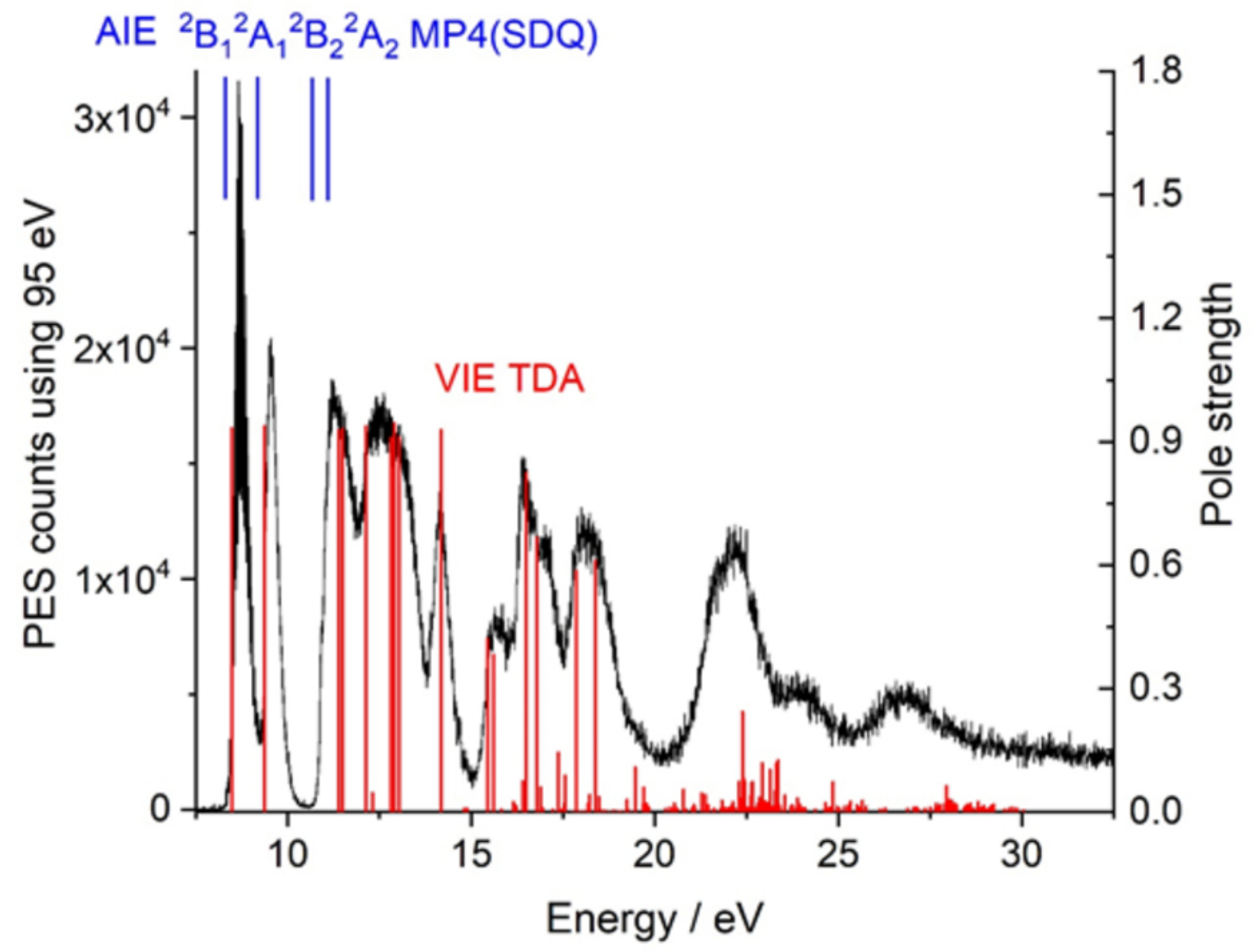


Figure9 Palmer et al

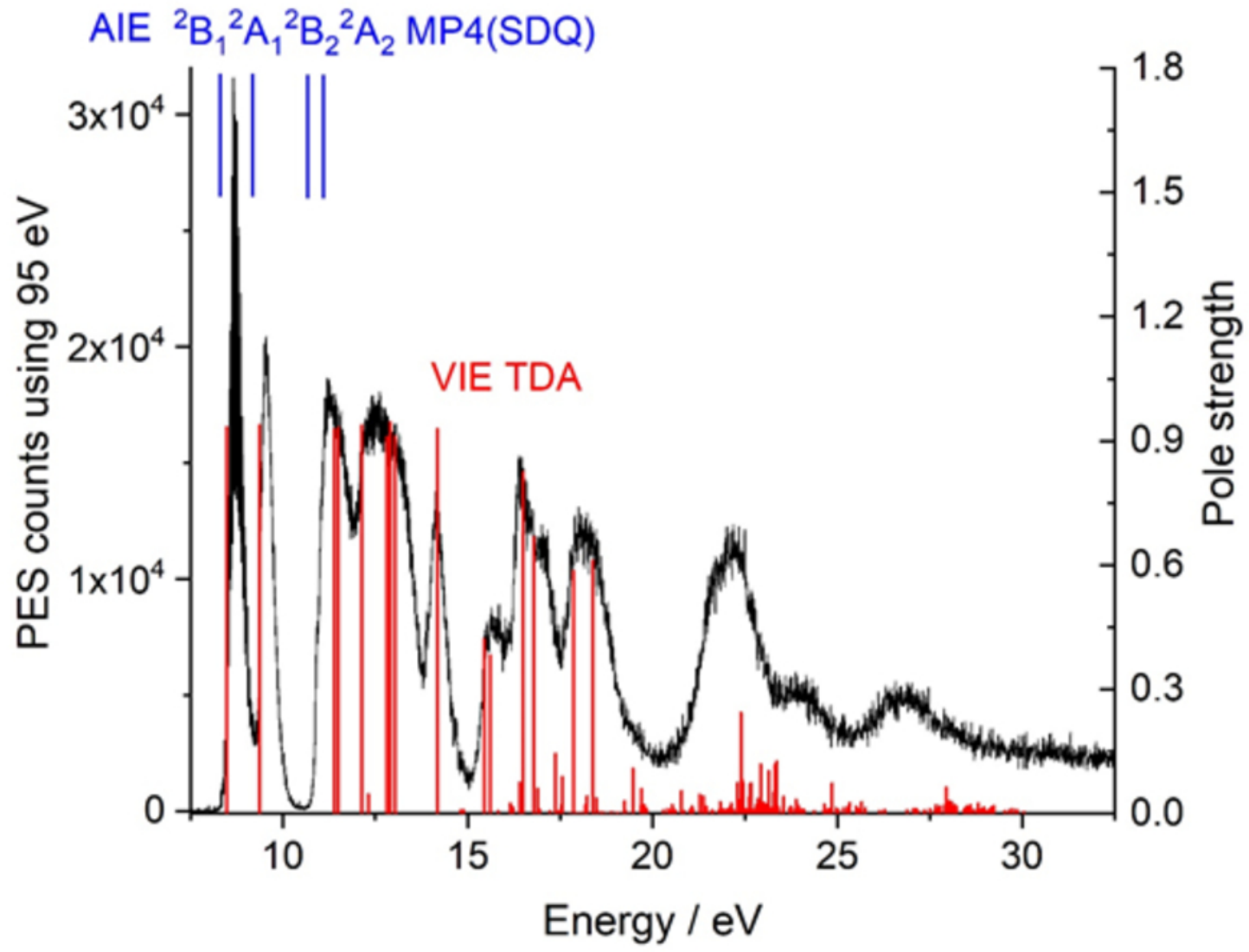


Figure 10. Palmer et al

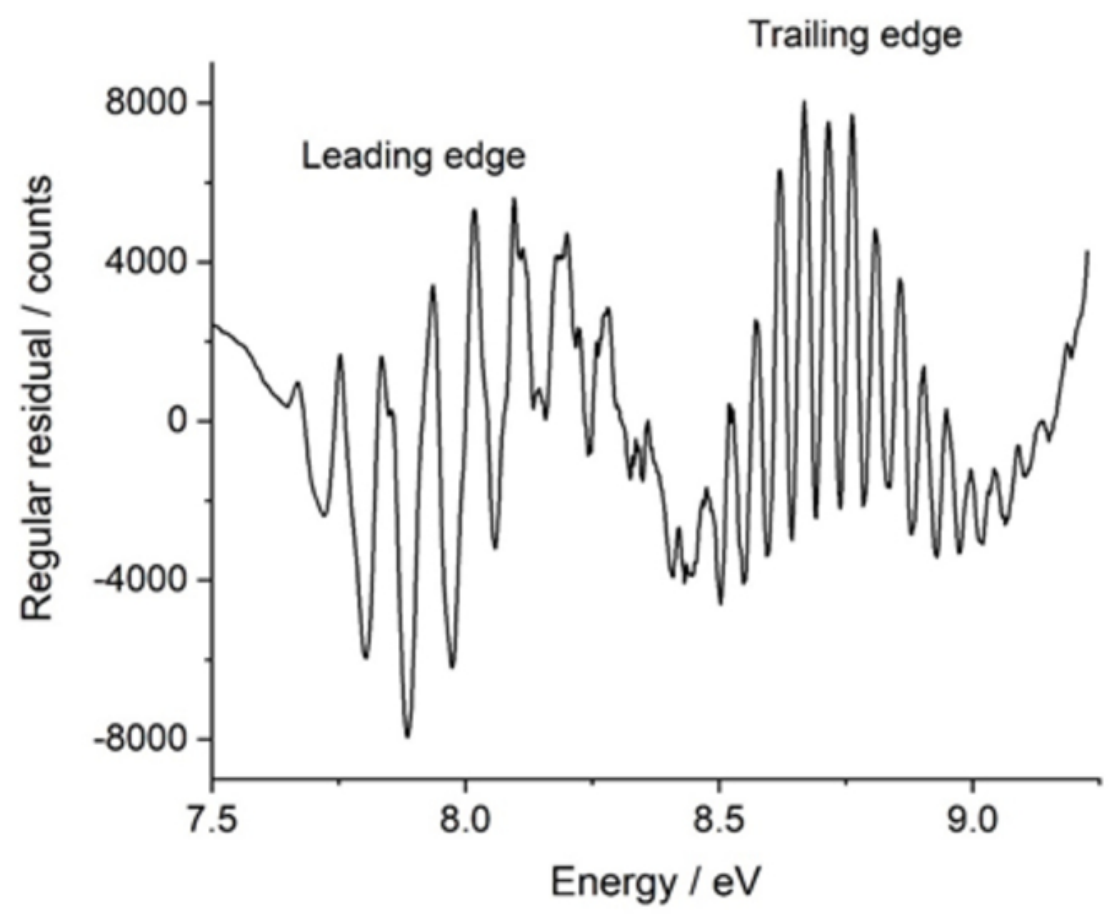


Figure 11. Palmer et al

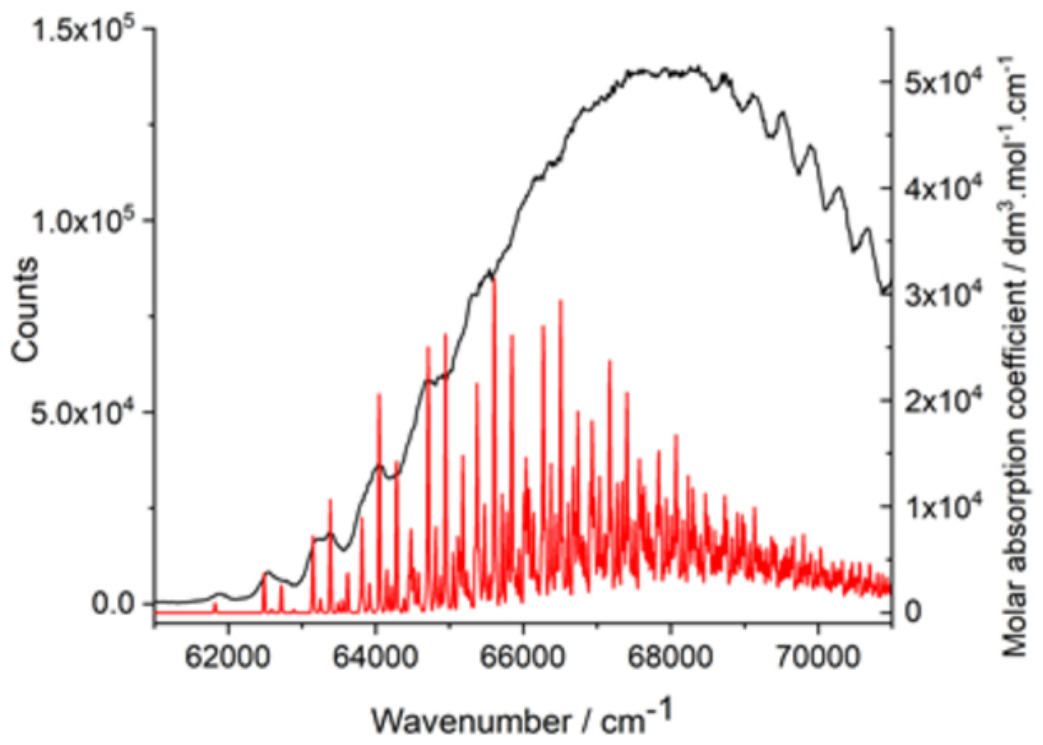


